\title{
REFLEXIONES EN TORNO AL MUNDO FUNERARIO DE LA ALTA ANDALUCÍA DURANTE LA TRANSICIÓN BRONCE FINAL-HIERRO I ${ }^{1}$
}

\author{
REFLECTIONS ON THE FUNERARY WORLD OF UPPER ANDALUSIA \\ DURING THE LATE BRONZE AGE-EARLY IRON AGE TRANSITION
}

\author{
por \\ Juan Pereira Sieso ${ }^{2}$ \\ TERESA CHAPA BRUNET ${ }^{3}$ \\ ANTONIO MADRIGAL BELINCHÓN ${ }^{3}$
}

RESUMEN

Este trabajo ofrece algunas reflexiones sobre los orígenes de las sepulturas de cremación que comienzan a aparecer en el Sureste de la Península Ibérica en el comienzo del primer milenio a.C. Tras algunos siglos sin evidencias significativas, se detectan algunos enterramientos de inhumación y cremación, siendo este último ritual el que se convertirá en el exclusivo de las comunidades locales. Estas transformaciones ideológicas se consideran como un proceso interno relacionado con los contextos políticos y económicos de las poblaciones ibéricas.

\begin{abstract}
This paper offers some thoughts about the origins of the cremation burials that begin to appear at the South-East of the Iberian Peninsula at the beginning of the first millenum B.C. After some centuries without any significant funerary evidence, some inhumation and cremation burials are detected, and this last ritual will finally develop to be the exclusive one among the local communities. These ideological transformations are considered as an internal processus related with the political and economical contexts of the Iberian populations.
\end{abstract}

Palabras claves

Key words
Andalucía Oriental, Bronce Final Edad del Hierro, rituales funerarios, inhumación, incineración.

Eastern Andalusia, Late Bronze Age-Iron Age, burial practices, inhumation, incineration.

\footnotetext{
1. Dedicamos el presente estudio al profesor Pellicer, cuyos trabajos pioneros han sido siempre referencia obligada para los nuestros. Además, su presencia en la zona que es aquí objeto de estudio fue fundamental para conocer yacimientos clave, entre otros, el de Galera, cuya secuencia del Bronce Final aún descansa en los trabajos que desarrolló junto a W. Schüle.

2. Área de Prehistoria. Facultad de Humanidades. Universidad de Castilla-La Mancha. Campus de Toledo. Pza. de Padilla 4. 45071 Toledo. jpereira@csh-To.uclm.es

3. Departamento de Prehistoria. Facultad de Geografía e Historia. Universidad Complutense. 28040 Madrid. tchapa@ghis.ucm.es
} 
El Sureste peninsular presenta, tras el final del mundo argárico y en los primeros compases del primer milenio a.C., un aparente "vacío", que trasluce cambios en el aprovechamiento del entorno y en las fórmulas simbólicas para expresar los papeles sociales. Al igual que en la fachada atlántica (Ruiz-Gálvez 1992: 240) se van a desarrollar procesos de interacción con los circuitos atlánticos, mediterráneos y continentales, lo que promoverá el conocimiento y aceptación de innovaciones tecnológicas, así como la valoración de ciertos recursos críticos y de las vías de su transporte, almacenamiento y eventual exportación. La progresiva rentabilización del trabajo agrícola -mayor rendimiento a igual esfuerzo- convertirá a la tierra en el principal factor de riqueza perdurable, lo que implica una opción importante para la desigualdad y un nuevo escenario en el que repartir los papeles sociales. Tenemos poca información sobre la organización de los asentamientos en esa época para la Alta Andalucía. Yacimientos como Galera (Pellicer y Schüle 1962 y 1966) y el Cerro de Cabezuelos (Contreras Cortés 1982; Molina, de la Torre, Nájera, Aguayo y Sáez 1979) nos presentan todavía un tipo de hábitat de grandes cabañas ovales en el que no puede reconocerse un urbanismo complejo, si bien introducen procedimientos de encalado y pintura en los zócalos, una costumbre que perdurará hasta la plena época ibérica.

En lo que se refiere al mundo funerario de este territorio (Fig. 1), desaparecen las pautas más o menos estables de las comunidades argáricas, para dar paso a un panorama en el que los restos funerarios no son abundantes. Se inicia un proceso de difuminación de las normas en el que podemos atender, entre otras, a ciertas dualidades, significativas: a) enterramiento/no enterramiento; b) inhumación/cremación; c) sepulturas individuales/múltiples; d) femeninas/masculinas; e) con/sin ajuar etc. En un primer momento no parece haberse recurrido a un proceso de enterramiento de la población, y la aparición del depósito de hachas de Arroyomolinos (Siret 1913; Monteagudo 1977) se tiende a paralelizar con depósitos semejantes del horizonte atlántico mas que como una manifestación funeraria (Fig. 2).

Posteriormente y durante la transición del Bronce Final al Hierro I, aparecen las evidencias del mundo funerario, si bien un sector significativo de las mismas aparece reflejado hasta el momento en un registro arqueológico caracterizado por una distribución irregular con carencias importantes, en la calidad y cantidad de las estructuras y ajuares documentados. La época, circunstancias y objetivos de los trabajos en que se documentaron los distintos contextos funerarios objeto del presente trabajo son factores que se han de tener en cuenta tanto en su análisis y estudio, como en las comparaciones que se pueden establecer con otros conjuntos funerarios que, o bien presentan una mayor homogeneidad, volumen de evidencias y contextualización (González Prats 2000) o, a pesar de las carencias del registro arqueológico aparecen circunscritos a unidades regionales a las que confieren una cierta personalidad (Lorrio 1985).

Independientemente de las estructuras funerarias y de sus elementos de ajuar gran parte de la discusión científica sobre este tipo de manifestaciones funerarias se ha centrado sobre los rituales funerarios practicados, entre los que se señalaba como rasgo significativo la aparición de la incineración. En la discusión sobre el origen y extensión del rito incinerador, para las necrópolis de la Andalucía Oriental se sugiere una relación más o menos directa con el mundo de los Campos de Urnas de la Península (Torres 1999: 149) o con algún punto del Mediterráneo (Molina 1978) que Bendala (1995: 261) al igual que para la Andalucía Occidental llega a vincular con los movimientos de los Pueblos del Mar en un momento precolonial en torno al siglo XII a.C.. Sin embargo en trabajos recientes, González Prats (2000; 2002: 391-399) presenta frente a la explicación habitual de la sustitución del ritual inhumador de tradición autóctona por el de incineración de procedencia foránea, evidencias que indican la utilización de la cremación en el sudeste peninsular desde la segunda mitad del II milenio a.C.. Propone también que un sector de las comunidades que utilizan este ritual lo hace en el marco de unas prácticas ceremoniales que no dejan huella en el registro arqueológico (González Prats 2002: 399). Esta alternativa en la que la cremación se presenta como un ritual utilizado más o menos regularmente por las comunidades de la fachada mediterránea peninsular del Bronce Final, se correspondería con un repertorio ritual funerario indígena más diversificado tal y como se documenta en las llamadas 
necrópolis de incineración del Sudeste en las que coexisten inhumaciones y cremaciones que en algunos casos son parciales (Lorrio 1985).

Estas manifestaciones funerarias del Sudeste peninsular presentan una serie de conexiones con la Cuenca Alta del Guadalquivir que permiten acrecentar el panorama funerario de la transición del Bronce Final al Hierro I con un conjunto de evidencias que configuran el siguiente catálogo.

\section{1.- FONELAS (GRANADA)}

Uno de los sepulcros de esta necrópolis megalítica, el conocido como Domingo I; fue reaprovechado en torno a fines del siglo IX o inicios del VIII a.C. para albergar una tumba múltiple (Fig. $1 \mathrm{n}^{\circ} 1$ ). La estructura trapezoidal de su cámara se separa de la norma habitual en estas construcciones, que suelen presentar planta rectangular o pentagonal. Tiene un corto corredor de acceso cerrado hacia la cámara por una losa. Las excavaciones dirigidas por Ferrer Palma (1977: 177-179) advirtieron que la construcción funeraria y su primera utilización correspondían a un momento del Calcolítico, cuando se practicó en su interior un enterramiento colectivo en el que se documentaron hachas planas metálicas. A fines del siglo IX a.C. el lugar fue de nuevo utilizado abriendo la estructura por su parte superior, para lo cual se debieron retirar la cubierta, lo que pudo provocar un derrumbamiento de la pared derecha, que fue reparada estrechando la superficie de la cámara. Los individuos enterrados en esta segunda fase fueron dos o tres, y sus huesos se encontraban desordenados. Algunos cúbitos y radios llevaban todavía asociadas las pulseras que decoraron los brazos de estas personas (Fig. $3 \mathrm{~A}$ ), recuperándose una serie de diez y otra de doce de estos adornos (Ferrer Palma 1978). Junto a los cadáveres aparecieron también 5 cuentas de collar de ópalo, 52 de bronce y una de cerámica pintada de negro, así como un remache, un zarcillo y un botón de bronce tipo Ría de Huelva.

\section{2.- BAZA (GRANADA)}

Las excavaciones que, por renuncia de M. Pellicer, llevó a cabo en el "Cerro del Santuario" de Baza F. Presedo (1982: 11-14) dieron como resultado la exhumación de una importante necrópolis ibérica (Fig. 1 $\mathrm{n}^{\circ}$ 2) que venía a completar los datos proporcionados en 1800 por el canónigo Pedro Álvarez sobre otro cementerio cercano, de mayor envergadura, situado sobre el llamado "Cerro Largo" o paraje de "Los Santuarios" (Sánchez Quirante 1999: 41). Aunque los trabajos llegaron cuando ya se había producido un considerable destrozo del yacimiento, se consiguió documentar de primera mano un importante número de sepulturas, entre las que destaca la $\mathrm{n}^{\circ} 155$ tanto por su ajuar como por la escultura femenina sentada que dominaba el espacio funerario (Presedo 1973). El excavador resalta al inicio de su memoria la riqueza arqueológica de la zona, haciendo alusión a restos argáricos junto al río, así como de muchos otros de época romana, algunos de gran envergadura (Presedo 1982: 12; Marín, Gener, Pérez y Puentedura 1993).

Lo que concentra nuestro interés en este caso es que, entre las tumbas ibéricas de cremación excavadas por Presedo en el Cerro del Santuario, se localizaron dos sepulturas de inhumación ( $n^{\circ}$ s 32 y 33 ) que rompen la homogeneidad ritual del conjunto restante (Fig. 4). Se trata de dos fosas con espacios diferenciados pero cuyas estructuras quedaban unidas por un piso "que se levantaba sobre el nivel de ambos unos $30 \mathrm{~cm}$ "(Presedo 1982: 59). La fosa $\mathrm{n}^{\circ} 32$ tenía unas dimensiones de 1,50 $\mathrm{m}$ de largo por 1,30 $\mathrm{m}$ de ancho. En su parte occidental se acumulaban cuatro cadáveres inhumados "con los huesos revueltos y sin corresponder a cuerpos enteros". El ajuar consistía "en unos cuantos fragmentos de cerámica negra a mano, muy basta, y unos fragmentos de aretes de bronce" (Presedo 1982: 59). La $\mathrm{n}^{\circ}$ 33, de dimensiones algo mayores si hacemos caso de su ilustración, contenía otros cuatro cadáveres dispuestos desordenadamente, y acompañados sólo por varias 
anillas de bronce fragmentadas (Fig. 2). En la memoria se afirma que cerraba su conexión con la tumba 32 mediante dos lajas de piedra verticales colocadas en el lado oeste, pero en el plano de la necrópolis esta descripción parece cuadrar mejor con la primera de las sepulturas descritas (Presedo 1982: 34, fig. 6).

Parece claro que éstas son las tumbas más antiguas de este lugar, y que podrían paralelizarse con el vecino yacimiento de Fonelas (Ferrer Palma 1977). No se conservan más indicios de esta época, quizás porque este nivel inicial pudo ser destruido por los usos posteriores del yacimiento -de hecho, las tumbas 32 y 33 se encuentran junto a los cimientos del gran edificio que a su vez se impone sobre la necrópolis ibérica (Presedo 1982: fig. 6)-. Sin embargo, resulta significativo que, tras un largo hiatus, uno de los cementerios del siglo IV a.C. vuelva a elegir el mismo emplazamiento, algo que no puede descartarse que ocurriera también en el vecino Cerro Largo.

\section{3.- CASTELLONES DE CÉAL (HINOJARES, JAÉN)}

La campaña realizada en este yacimiento por C. Fernández Chicarro y A. Blanco en 1959 (Chapa et alii, 1998) logró detectar el primer nivel de ocupación de la necrópolis, revelando así la existencia de un pequeño asentamiento que implanta y practica el ritual de la cremación aparentemente de forma exclusiva. El poblado debió situarse en la parte alta del cerro mientras que la necrópolis fue emplazada en la zona inferior, inmediatamente por encima que cae a plomo sobre el río Céal. El lugar domina la confluencia entre este curso fluvial y el Guadiana Menor (Fig. $1 \mathrm{n}^{\circ} 3$ ), existiendo a sus pies un vado estratégico en las comunicaciones entre el Alto Guadalquivir y las altiplanicies granadinas. A una profundidad de 4,25 m respecto a la superficie se documentaron una serie de tumbas -al menos cuatro- en las que junto a la pira fue depositada la urna -cazuelas abiertas en tres casos y una imitación de una ánfora de hombro marcado con asas verticales en el cuarto-con un ajuar que consistía en algunos adornos, como aros o collares, y en fíbulas de bronce de doble resorte (Fig. 5 ).

No se conocen datos sobre el tipo de viviendas en el que residían estas personas, ya que los niveles posteriores han borrado aparentemente todo vestigio de esta fase antigua. En todo caso, las tumbas quedaron sepultadas en este nivel en la segunda mitad del siglo VII o inicios del siglo VI a.C., abandonándose el lugar hasta la transición hacia el siglo IV a.C. En este lapso de tiempo se acumuló hasta 1,5 m de sedimento, puesto que las tumbas ibéricas documentadas por Fernández-Chicarro no superaban los $3 \mathrm{~m}$ de profundidad, lo que implica la existencia de un fuerte proceso de erosión, aumentando quizás en el momento de la refundación del lugar. La similitud de ritos y materiales con la necrópolis de Las Tosquillas de Cerro Alcalá es manifiesta, como también los el hecho de que los mismo lugares siguieran sirviendo como cementerios largo tiempo después y tras épocas de abandono.

\section{4.- TUGIA (TOYA-HORNOS, JAÉN)}

Se sitúa este enterramiento en una zona baja, a los pies del Cerro de la Horca (Fig. $1 \mathrm{n}^{\circ}$ 4). Se indica la presencia de una necrópolis expoliada, en la que Mergelina abrió unas catas aprovechando precisamente las zanjas de la expoliación. A $4 \mathrm{~m}$ de distancia del camino y a 1,20 m de profundidad respecto a la superficie actual se localizó una acumulación de grandes cantos rodados que rellenaban una fosa $\mathrm{de} 1 \mathrm{~m}^{2}$. Este relleno se apoyaba contra una losa de piedra conservada aún en posición vertical y que daba paso a una cámara excavada en el sedimento. La losa medía $89 \mathrm{~cm}$ de alto, $66 \mathrm{~cm}$ de ancho en su base y $55 \mathrm{~cm}$ en la parte superior, con un grosor medio de $15 \mathrm{~cm}$. Su cara interna se encontraba decorada con cuatro círculos concéntricos, apreciándose una escotadura en $\mathrm{V}$ en el exterior. El espacio sepulcral es subcircular y de 
techo abovedado, con una anchura de $1,50 \mathrm{~m}$, un fondo de $1,35 \mathrm{~m}$ y una altura de $89 \mathrm{~cm}$, estando su entrada orientada al suroeste (Fig. 3 B).

No parece que las circunstancias de la excavación permitieran una documentación detallada del hallazgo, que consistía en una serie de inhumaciones -cinco como mínimo a juzgar por el número de cráneos-, y un escaso ajuar metálico formada por pulseras de bronce. Aunque el croquis ofrecido por Mergelina (19431944: fig. 7) hace pensar en deposiciones primarias, la descripción alude más bien a "paquetes" de huesos, y de hecho el excavador propone un uso consecutivo del enterramiento, en el que primero se habrían introducido dos individuos y luego otros tres, desplazando a los anteriores. Un arete de bronce situado junto al cráneo del fondo es interpretado como un posible pendiente, mientras que dos conjuntos de dos y tres brazaletes respectivamente -en los que no se hace alusión a decoración alguna- se asociarían a otros dos individuos. Aunque la tierra de relleno fue cribada, no se recogió ningún otro objeto, si bien se habían documentado fragmentos cerámicos de color negruzco y superficie bruñida entre los cantos que sellaban el acceso a la sepultura y que correspondían a una cazuela de carena alta.

Mergelina (1943-1944:30) sitúa cronológicamente este hallazgo en el Bronce Final, y relaciona la lápida de cierre con las estelas extremeñas, indicando que su expansión alcanza áreas tan alejadas como ésta del oriente andaluz. Recogida por Fernández-Oxea (1950: 293), es de nuevo incluida en el corpus de S. Celestino (2001: 414, $n^{\circ} 69$ ), vinculándola a ejemplares de la zona de Córdoba. La afirmación de que en este lugar se habían expoliado otras tumbas hizo pensar a Mergelina en la existencia de una necrópolis, lo que significaría un recurso sistemático al enterramiento múltiple, aunque el alcance de este fenómeno nos es desconocido. Es significativa, en todo caso, la elección de un emplazamiento próximo al río de Toya, y en el entorno de lo que luego se convertirá en una extensa necrópolis de época ibérica, en la que se vuelve a recurrir, dentro de los sepulcros monumentales, a la asociación de varios individuos.

En un momento inmediatamente posterior se recurrirá en el área de Toya a un sistema de enterramiento bastante diferente empleando la cremación de los cadáveres y su introducción en cámaras tumulares emplazadas en lugares de máxima visibilidad. Es el caso del doble enterramiento de incineración de la cámara de Hornos recientemente excavada, fechable en la segunda mitad del siglo VII a.C., y que marca el inicio de una tradición que se mantendrá largo tiempo en la zona ${ }^{4}$

\section{5.- CERRO ALCALÁ (TORRES, JAÉN)}

Este importante asentamiento (Fig. $1 \mathbf{n}^{\circ}$ 5), situado junto a la carretera que une Mancha Real y Jimena, ha sufrido numerosos episodios de destrucción a lo largo del tiempo, tanto por la búsqueda incontrolada de materiales arqueológicos como por los trabajos agrícolas y las infraestructuras a ellos asociados, que han alterado el subsuelo de forma importante. El lugar reviste un gran interés, ya que parece haber evidencias de su uso continuado desde el Bronce Final hasta el Ibérico Pleno y Tardío, por lo que supone un excelente campo para el estudio diacrónico de los cambios culturales a lo largo del primer milenio a.C.

Los hallazgos más antiguos corresponden a sepulturas individuales o dobles, en pozos más o menos profundos, que emplearon el ritual de la cremación, introduciendo los huesos quemados en urnas y acompañándolas de ciertos elementos de ajuar (Fig. $6 \mathrm{~A}$ ). Además de la recogida de diversos materiales, Carrasco, Pachón, Pastor y Lara (1980: 223) pudieron documentar dos tumbas completas, ambas dobles. Una de ellas incluía dos juegos de urna, cuenco y fuente de borde recto saliente y carena alta, todo ello de superficie muy bruñida, y la otra dos urnas ovoides, tres platos y una fíbula de codo. Los autores paralelizan estas cerámicas con las de los yacimientos de otras áreas cercanas, como el Cerro de Cabezuelos o Úbeda

4. Agradecemos diversas informaciones sobre la cámara proporcionadas por M. Castro, M. Molinos y A. Ruiz. 
la Vieja, en la desembocadura del Jandulilla, así como con los yacimientos granadinos de Galera o Cerro de la Mora, fechándolas en torno al s. IX a.C., si bien esta cronología podría ser más tardía.

Estos testimonios más antiguos dan paso a otra evidencia funeraria procedente de este yacimiento y que podría situarse entre la segunda mitad del siglo VII e inicios del siglo VI a.C. Se trata de las sepulturas excavadas -esta vez de forma sistemática-en la necrópolis de "Las Tosquillas", al suroeste de cerro Alcalá y separada de este por una vaguada. Además de tumbas tumulares de cierta entidad correspondientes al Ibérico Pleno se documentaron algunas sepulturas y materiales en las que los huesos quemados eran introducidos en una urna sin cubrir acompañándose por un vaso de ofrendas y otros elementos, como cuchillos de hierro o fíbulas de doble resorte (Fig. 6 A). Entre las urnas se documentó un ejemplar del "Tipo Toya" y otras cazuelas abiertas similares a las encontradas en Los Castellones de Céal (Negueruela Martínez, Rodríguez Rus y Avella Delgado 1987: 296).

Después de un vacío correspondiente al siglo $\mathrm{V}$ a.C., momento en el que no se conoce ninguna sepultura, el asentamiento recupera este espacio funerario en los inicios del siglo IV a.C. y genera otro, en la vertiente opuesta del cerro Alcalá, donde se practicaron sepulturas de cremación con materiales similares a los de Las Tosquillas. Esta nueva necrópolis, enclavada en el lugar denominado como la "Era Alta de Caniles", sigue sin embargo costumbres rituales algo diferentes, con tumbas de fosa revestidas de adobes y quemaderos de grandes dimensiones, desconociéndose aquí los empedrados tumulares (Negueruela Martínez y Rodríguez Rus 1986: 390) y revelando, por tanto, lo que puede ser un indicio de agrupaciones sociales de distinta condición conviviendo en el mismo lugar.

\section{6.- CÁSTULO (LINARES, JAÉN)}

Las diversas campañas realizadas de la antigua ciudad de Cástulo(Fig. $1 \mathrm{n}^{\circ}$ 6) han confirmado sin excepción la importancia que adquirió este lugar a partir del final de la Prehistoria, como centro ciudadano vinculado estrechamente a las explotaciones mineras d Sierra Morena Oriental. La etapa del Bronce Final indígena es la que recibe un importante impacto por parte del mundo colonial fenicio, que como en otros lugares, supondrá un salto cualitativo en la producción industrializada y artesa, en los modos de vida y organización social y , paralelamente, en el campo de la ideología religiosa. Tres son la áreas funerarias que parecen reconocerse en este momento: Los Patos, Estacar de Robarinas y Los Higuerones (Blázquez y Valiente 1982 con las referencias bibliográficas). Su distribución es de nuevo coherente con la que existirá en época ibérica, ya que en todos estos lugares existirán de nuevo necrópolis a partir de finales del siglo $\mathrm{V}$ a.C. No sucede lo mismo con los momentos anteriores, para los que no hay testimonios funerarios, lo que parece habitual en esta y otras zonas. De hecho, en el caso de Los Patos (Fig. 7) se pudo observar que la primera necrópolis se asienta sobre un área previamente utilizada como hábitat o zona de trabajo, lo que supone una transformación notable en el uso del espacio, y probablemente un proceso de "sinecismo aldeano", como ya han descrito Ruiz y Molinos (1993: 264). Las tumbas antiguas están muy afectadas por la erosión y por las posteriores reocupaciones de estos lugares, pero es posible apreciar que se recurre de forma generalizada al ritual de la cremación, asociada a los primeros elementos de hierro, que generalmente consisten en armas. El ambiente inicial no parece revelar diferencias notables en los ajuares que no sean otras que el mero acceso al enterramiento. No sucederá lo mismo en los siglos VII y VI a.C. cuando nos encontremos con tumbas de ajuares más que notables, como el túmulo de Los Higuerones (Blázquez 1975: 263-267), o los hallazgos del Estacar de Robarinas, parcialmente publicados por Blanco (1965).

Estos primeros lugares de enterramiento encuentran su referente en el área conocida como la Muela (Blázquez y Valiente 1981; Blázquez, García Gelabert y López Pardo 1985) situada en un punto central entre los dos yacimientos anteriormente citados, y muy ligada como ellos al curso del río Guadalimar, que 
probablemente jugó un papel crucial en el planteamiento estratégico de toda la región. En esta zona se reveló una compleja estratigrafía de la que su fase I está vinculada a los hallazgos que encontramos en la necrópolis de Los Patos o a los que aparecen en otras necrópolis de la zona, como Cerro Alcalá o Céal. Las cazuelas de cerámica oscura o las fíbulas de doble resorte aparecen aquí conviviendo con otras cerámicas a torno, a veces decoradas con pintura geométrica, con cerámicas a mano con decoración bruñida, grafitada y pintada, así como a objetos de hierro. Resulta de gran interés recordar que todos estos materiales se asocian a una acumulación de unos $7 \mathrm{~kg}$ de galena argentífera, lo que revela la vinculación del lugar a la transformación de productos mineros. La construcción sobre estos niveles del santuario con un pavimento de guijarros que está vigente durante fines del siglo VII y siglo VI a.C. revela una ritualización aparejada a una mayor complejidad urbanística y social que esta acorde con lo ya expuesto para el mundo funerario. En cualquier caso, todo indica que Cástulo fue el gran centro del Alto Guadalquivir, desde el cual se establecieron vías de acceso tanto hacia el sureste como hacia el sur y la Baja Andalucía.

\section{7.- JAÉN}

Con motivo de una intervención arqueológica en el casco urbano de la ciudad de Jaén (Fig. 1) se documentaron una serie de niveles arqueológicos en uno de los cuales se documento un enterramiento que hasta el momento permanece inédito ${ }^{5}$. El enterramiento en cuestión estaba formado por una fosa sin ningún tipo de tratamiento especial en suelo y paredes y tapada con una losa de piedra. En el interior se efectúo un enterramiento de incineración mediante una urna cineraria a mano de base plana, pasta gris y superficies bruñidas que actuaba como contenedor de los restos cremados de una persona adulta de la que no se ha podido precisar el sexo y la edad. La urna cineraria que no llevaba tapadera se depositó sobre un plato de similares características técnicas similares a las de la urna, con el borde engrosado y una doble perforación en la zona del borde. Junto con los restos óseos se documentaron en el interior de la urna una pulsera de bronce de sección romboidal y decorada con pequeñas incisiones, un pequeño cuenco a mano de pasta marrón rojiza y un cuerno de cabra. Este conjunto se encuadraría en el Bronce Final con una cronología en torno ala primera mitad del siglo VII a.C.

\section{8.- LA GUARDIA (JAÉN)}

En la periferia de la necrópolis ibérica del Ejido de San Sebastián (Blanco 1959) que domina la desembocadura del río La Guardia en el Guadalbullón paso natural que conecta la Campiña alta con Granada (Fig. 1), se excavó de urgencia una estructura funeraria que todavía permanece inédita ${ }^{6}$. La información de la que disponemos señala que se trataba de una estructura aislada que presentaba huellas de los trabajos que habían propiciado su descubrimiento casual. Su morfología era la de una fosa ovalada con un eje máximo de $1,20 \mathrm{~m}$ de largo que presentaba en su interior un nivel de cenizas con una potencia máxima de $10 \mathrm{~cm}$. Sobre esta capa de cenizas se documentaron los recipientes cerámicos en un estado de fragmentación que no ha impedido su completa reintegración. Se trata de un conjunto de vasos de cerámica a mano, de color oscuro y superficies bruñidas formado por una gran urna con cuello ligeramente acampanado, un cuenco carenado y una fuente o plato con decoración de retícula bruñida en la que predominan los motivos de rombos. El resto del ajuar de este enterramiento estaba compuesto por un pequeño brazalete de bronce sin decoración

5. Debemos los datos sobre este enterramiento a la amable colaboración de M.A. de Dios.

6. Debemos la información sobre este enterramiento a la amable colaboración de M. Molinos. 
de sección cuadrada; una lámina de bronce; fragmentos de bronce de una posible fíbula; 4 cuentas de collar y una fusayola en hueso de sección semiesférica.

La abundante presencia de cenizas y la localización del fragmentado ajuar cerámico sobre las mismas, permiten suponer el desarrollo de un ritual de incineración en el que la urna cineraria se depositó sobre los restos del quemadero, que tras su cubrición se convierte en tumba. Falta sin embargo una mayor precisión sobre las características de los restos de cenizas que permitan confirmar esta propuesta de reconstrucción. Por lo que se refiere al ajuar cerámico, recuerda en su composición a los enterramientos de la fase más antigua de Cerro Alcalá (Fig. $5 \mathrm{~B}$ ), en los que el recipiente de perfil cerrado actúa como contenedor y el cuenco o plato de mayor tamaño de tapadera del mismo, siguiendo una pauta de utilización normalizada en las necrópolis del Sudeste (Lorrio 1985) (González Prats 2002: 267), en la que no desentonan los demás elementos del ajuar.

El conjunto de materiales de esta tumba se puede relacionar con los del nivel III del Cerro de los Infantes atribuido al Bronce Final Pleno (Molina et alii 1983: 692-3) en el que destacan las cerámicas de retícula bruñida, las vasijas globulares con cuello marcado y elementos metálicos como las pinzas de depilar y la fíbula de codo, con una cronología entre el 900 y el 750 a.C..

\section{9.- CORTIJO DE LAS TORRES (MENGÍBAR, JAÉN)}

Se localiza esta necrópolis al sur del Cortijo de las Torres en la orilla izquierda del Guadalquivir, muy cercana al espectacular asentamiento de Cerro Máquiz (Fig. 1). Los datos sobre el yacimiento son escasos y hacen referencia al predominio del rito incinerador durante todo el período de utilización de la necrópolis desde el Bronce Final hasta época romana (Carrasco, Pachón y Aníbal 1986: 202). Para la fase más antigua se conoce la utilización de fosas de distinta profundidad en las que se depositaban las urnas de incineración de variada tipología entre las que destacaban vasos en forma de copa, ollas, fuentes de carena alta, cuencos y un vaso chardón (Carrasco y Pachón 1986: 374). Estas piezas realizadas a mano y de superficie bruñida aparecen junto algunos elementos metálicos ( Fig. 8. A) como punzones de bronce, aretes y un botón de bronce tipo Ría de Huelva que permitirían fechar esta primera fase de ocupación entre finales del siglo IX y la primera mitad del siglo VIII a.C. (Ruiz-Gálvez 1995: Lám. 11). Un segundo conjunto integrado por materiales importados como ampollas fenicias y platos de engobe rojo, permiten constatar el horizonte de penetración y contacto de las manufacturas orientalizantes documentado en otros yacimientos de la Alta Andalucía así como precisar la continuidad de uso de la necrópolis en la transición del siglo VIII al VII a.C. Por último habría que incluir la publicación de una serie de recipientes cerámicos, que a pesar de sus carencias en cuanto a su contextualización amplían de manera significativa el repertorio de vasos cerámicos de la necrópolis (Carrasco, Pachón y Aníbal 1986). Destacan todos ellos por su factura a mano y sus espectaculares decoraciones monócromas y bícromas sobre formas características del ámbito funerario como el vaso chardón, un cuenco de suave carena alta y una curiosa bandeja con seis receptáculos circulares (Fig.8. B,C y D) constituyendo estos dos últimos ejemplares uno de los paralelos más claros de algunas de las piezas más significativás de la posible tumba XIX de Los Patos. La cronología que sitúa este tipo de piezas en la primera mitad del siglo VIII a.C. (Molina 1978: 217-218) (Ruiz Gálvez 1995: 83) podría ampliarse hasta finales del mismo siglo, lo que permitiría señalar esta necrópolis y el asentamiento de Cerro Máquiz al que debe pertenecer, como uno de los conjuntos claves para entender el proceso de transición del Bronce Final al Hierro en la Alta Andalucía. 


\section{0.- CERRILLO BLANCO (PORCUNA, JAÉN)}

La venta en el año 1975 de una serie de esculturas ibéricas de extraordinaria calidad al entonces director del Museo Provincial de Jaén, D. Juan Gonzáles Navarrete; puso sobre aviso de la existencia de un importante yacimiento en el entorno de Porcuna. Éste se sitúa en un promontorio conocido como "Cerrillo Blanco", que se levanta dominando el paisaje de lomas propio de esta zona fronteriza de la Campiña, entre Córdoba y Jaén (Fig. $1 \mathrm{n}^{\circ} 10$ ). El lugar fue empleado en diversas etapas con muy distintos fines. En época reciente mantenía una explotación de olivar que afectó en cierta medida al subsuelo, documentándose como nivel anterior una ocupación de tiempos medievales. Ésta se superpone al último momento de la necrópolis ibérica, de la que se recogieron materiales cerámicos locales e importaciones áticas que permiten atribuirla al Ibérico Pleno, en torno a la primera mitad del siglo IV a.C.. En la tumba de cámara de esta fase se reutilizaron algunos fragmentos escultóricos correspondientes a la etapa precedente que debieron quedar a la intemperie, a juzgar por su estado de rodamiento (Torrecillas González 1985: 38). Muchos de ellos, sin embargo habían quedado cuidadosamente preservados en una zanja abierta en la ladera occidental del cerrillo, en donde fueron introducidos una vez fragmentados, y cubiertos después mediante losas, lo que ha permitido que sus superficies lleguen en buen estado de conservación hasta nosotros. El estudio de estas piezas(González Navarrete 1987; Blanco 1987, 1988 a y 1988b; y sobre todo Negueruela 1990), fechadas dentro del siglo V a.C., ha permitido reconocer varios conjuntos de representaciones, todos ellos de gran calidad y de los que apenas podemos atisbar las complejas composiciones que representaron y el escenario arquitectónico al que pertenecieron. Lo que sí está claro es que se asociaron voluntariamente al cementerio que en una época anterior, en torno a los siglos VII-VI a.C., tuvo lugar en la cima del cerro. Esta necrópolis, de la que se excavaron 24 tumbas individuales y una cámara doble, todas ellas de inhumación, se instaló a su vez sobre niveles del Bronce Final, en los que se documentaron además de algunos objetos materiales, una serie de silos de almacenaje. Este momento parece constituir la ocupación más antigua de este promontorio, y aquella de la que arranca su uso posterior.

El yacimiento del Cerrillo Blanco es sólo uno de los puntos significativos del poblamiento de una zona que parece cumplir un papel clave en las transformaciones políticas, sociales, culturales, económicas y religiosas que se aprecian en esta zona de las Campiñas. Los trabajos continuados de Arteaga (1999) en el área de Porcuna le han llevado a proponer una secuencia interpretativa de estos cambios, apreciándose sobre el sustrato del Bronce Final, y desde fines del siglo VIII a.C. una clara vinculación al mundo tartésico occidental, lo que se refleja en novedades importantes en el sistema de poblamiento, con una concentración poblacional en el Cerro de los Alcores en detrimento del vecino Cerro del Albalate y de los enclaves rurales preexistentes. La nueva aristocracia de corte tartésico incorpora novedades urbanísticas, con programación de espacios regulares trazados desde calles rectilíneas, así como novedades tecnológicas vinculadas al uso del hierro o al empleo del torno alfarero. La aparición de decoraciones figurativas de tema orientalizante hace pensar en transformaciones de índole religiosa que tienen su parangón en el Bajo Guadalquivir. A finales del siglo VII e inicios del siglo VI a.C. se vuelven a instalar pequeñas explotaciones de carácter rural que parecen seguir el patrón conocido en Las Calañas de Marmolejo (Molinos et alii 1994), aunque los trabajos en Porcuna proponen la existencia de una dualidad en la ocupación de la tierra según se trate de secano o regadío (Arteaga 1999: 112). En todo caso, se aprecian nuevas fórmulas de poder que se reflejan en el control, reparto y explotación de los recursos primarios, entre los que se encuentran la tierra y su producción agrícola, el ganado y las minas.

Una muestra física de la nueva configuración de los grupos dirigentes la tenemos en la necrópolis orientalizante de Cerrillo Blanco, en donde los enterramientos revelan un uso continuado del espacio (Fig.9 $\mathrm{n}^{\circ} 1$ )por parte de un grupo familiar bastante cerrado, a juzgar por el estrecho parentesco que revela el estudio de los huesos (Arteaga 1999: 113). La sepultura principal parece ser una tumba de cámara (tumba A de 
Torrecillas González 1985: 103-104) en la que se delimitó mediante lajas de verticales de piedra un espacio circular de suelo enlosado con un soporte pétreo central para sostener la cubierta (Fig $9 \mathrm{n}^{\circ} 2$ ). En su interior fueron depositados dos cadáveres, de hombre y mujer (Arteaga 1999: 114), sin acompañamiento de ajuar. Los restantes individuos enterrados incluyen a hombres, mujeres y niños, muchos de ellos también sin ajuar, aunque otros incluyen algunos objetos personales relacionados con el vestido (fíbulas, broches de cinturón), cabello (agujones, peine de marfil), adornos (collares) o cuchillos de hierro. Todos ellos podían ser llevados sobre el cuerpo de los difuntos en el momento de enterramiento, sin que se añadieran otras piezas específicamente funerarias, como vasos cerámicos o recipientes metálicos. La estructura de las tumbas, exceptuando la cámara, es así mismo muy sencilla, tratándose de fosas abiertas con escaso cuidado y tapadas de nuevo con la tierra extraída y con piedras (Fig.9 $\mathrm{n}^{\circ} 3$ ), a las que pudieron añadirse estelas que fueron derruidas, cayendo por la pendiente y quedando depositadas en el contorno del cabezo (Torrecillas González 1985: 23). Este grupo que ostenta elementos de clara raigambre tartésica, como el peine de marfil con decoración zoomorfa o los broches de cinturón y fíbulas de doble resorte, sitúa su cementerio en un lugar significativo, que había sido dedicado anteriormente a la explotación y almacenamiento agrícola. Es evidente que el modelo de ocupación del espacio y la configuración social han variado de forma sensible, y puede que éste sea un caso en el que se documente en cierta manera la privatización de una antigua propiedad comunal.

No parece que este ambiente tartésico se adelante más en la zona de Andalucía Oriental. Arteaga (1999: 110) sitúa en el río Guadalbullón la frontera con el territorio dominado por Cástulo, que responde manera diferente a los estímulos de la colonización fenicia de la costa. Esta antigua vinculación con el suroeste peninsular quedaría reflejada en aspectos como la toponimia estando Ipolca-el antiguo nombre de Porcunamás relacionado con el mundo occidental de la Turdetania que con el Alto Guadalquivir (Untermann 1985: 14). Sin embargo, su carácter de límite favorecerá que en las épocas siguientes, a partir del siglo V a.C., este territorio quede afectado por las transformaciones que modelo social regido por las aristocracias de carácter guerrero que fueron plasmadas en los conjuntos escultóricos del Cerrillo Blanco (Ruiz1998: 294). La existencia de este monumento, de marcado carácter heroico y conmemorativo, así como la necrópolis de incineración que se desarrolla posteriormente sobre los enterramientos orientalizantes indica un significativo cambio ideológico que encuentra sus paralelos más próximos en el área oriental giennense, lo que revela el dinamismo expansivo del ámbito cultural ibérico hacia las sierras y la campiña cordobesa.

\section{ANÁLISIS Y PERSPECTIVAS DE FUTURO}

En primer lugar cabría señalar la relativa representatividad de los enterramientos catalogados que unas veces, corresponden a conjuntos documentados en fases o inicios de proyectos que o bien no han tenido continuidad o se orientaron hacia el estudio de un sector o fase distinta de la necrópolis. En otros casos se trata de hallazgos aislados fruto de intervenciones de urgencia cuando no de conjuntos descontextualizados. Este panorama afecta de manera significativa a las consideraciones que hagamos, puesto que somos conscientes que nuevos hallazgos mejor contextualizados y con la aplicación de nuevos protocolos analíticos pueden modificar de manera importante algunas de las conclusiones que propongamos. Caso aparte es el del Cerrillo Blanco. En él se ha documentado un espacio cerrado correspondiente al uso que de él hace un sector de la comunidad unido por lazos de parentesco. Esta organización del área funeraria con reserva de espacio para grupos concretos independientemente del ritual empleado tiene sus paralelos en el mundo orientalizante de la Baja Andalucía en Setefilla (Aubet 1975; 1978 ) y Las Cumbres (Ruiz y Pérez 1989; 1995).

En el resumen que presentamos en el Mapa de dispersión (Fig. 1) y en la matriz sobre rituales, estructuras y cronología (Fig. 10) de estas manifestaciones funerarias cabría resaltar en primer lugar la distribución geográfica de las mismas en torno al Valle del Guadalquivir y las depresiones granadinas con Porcuna 
al oeste, Cástulo al Norte -con la posible coexistencia de inhumación e incineración- y Baza al este con enterramientos de inhumación que triangulan un territorio en cuyo interior sólo aparecen tumbas con el ritual de incineración. Las características de esas evidencias funerarias parecen indicar la utilización del ritual de la incineración en momentos anteriores al desarrollo del mundo tartésico orientalizante en la Andalucía Occidental y asociado a la presencia de elementos que se contextualizan en el marco del Bronce Final Precolonial (Torres 1999: 75: fig. 30; Ruiz-Gálvez 1995).

En cuanto al desarrollo de estas manifestaciones funerarias durante los siglos VIII y VII a.C. parece producirse un proceso que se caracteriza en su arranque por la ausencia de homogeneidad, recurriéndose tanto a la cremación como a la inhumación, sin que parezca dominar una normativa compartida, sino diferentes sistemas que pueden responder a tradiciones más o menos arraigadas. Lo que se advierte, en todo caso, es que vuelve a hacerse necesaria una presencia física permanente de los antepasados difuntos en el medio en el que se desarrolla la vida, no ligándolas ya a las viviendas, como en tiempos argáricos, sino emplazándolos en puntos alternativos al poblado, a menudo estratégicos en relación con las vías de tránsito o con recursos específicos.

Desde la variabilidad de rituales, enterramientos y ajuares (Fig. 10) parece manifestarse una tendencia hacia una cierta unificación, durante la segunda mitad del siglo VII y el inicio del VI a.C., en la que la cremación del cadáver se irá convirtiendo en el rito dominante hasta hacerse exclusivo. El proceso de la cremación supone una manipulación más elaborada de los difuntos por parte de la comunidad, ya que los cadáveres deben ser convertidos en restos calcinados para permitir su adecuado tránsito al más allá, sin que esto implique una pérdida de complejidad en la formalización de la sepultura. Se va a ir desarrollando una creciente ritualización y un alargamiento del proceso funerario que precisa de medios específicos y posibilita una participación colectiva más prolongada, por lo que se convierte en un campo muy abierto para reforzar la cohesión y a la vez estimular la competición social.

En este largo proceso de unificación parecen configurarse fórmulas diversas y tentativas que afectan a pocos individuos, aunque suponemos que éstos son utilizados para fijar ideologías y obtener situaciones de ventaja socio-económica, como los enterramientos dobles tanto de inhumación como de incineración de Cerrillo Blanco, Hornos y Estacar de Robarinas (Cástulo), que también aparecen en la Baja Andalucía (Bonsor 1899; Sánchez 1994). Estas semejanzas con estructuras funerarias del mundo funerario de la Andalucía Occidental se hacen también extensivas a los ajuares como las que se aprecian entre los enterramientos de Céal y la segunda fase de Cerro Alcalá con los de los túmulos A y B de Setefilla (Aubet 1975; 1978).

La consolidación de este proceso en los inicios del Horizonte Ibérico durante el siglo VI, se mantiene durante el siglo $\mathrm{V}$ en cuanto a una selección del número de enterramientos por tumba y restringiendo de modo evidente el número de estructuras funerarias(Chapa, Pereira y Madrigal, e.p.). Será a partir del inicio del siglo IV cuando asistimos a la aparición de las grandes necrópolis con un gran volumen de enterramientos, en los que si bien nunca estuvo representada la totalidad de la población, en el caso de las necrópolis del Guadiana Menor se caracterizan por un porcentaje significativo de enterramientos múltiples (Pereira, Madrigal y Chapa 1998).

En otro orden de cosas los contextos funerarios del Bronce Final-Hierro de Porcuna, Mengíbar, Cástulo, Cerro Alcalá, Toya, Céal y Baza constituyen el arranque de necrópolis de secuencia amplia que se prolongará durante toda la Edad del Hierro hasta la romanización. Esta circunstancia parece sugerir que durante este proceso de transición se produjo la elección por parte de distintos grupos de un sector de los territorios donde se asientan ex novo, que queda reservado y consagrado para su uso funerario por generaciones incluso en los casos en los que los emplazamientos quedan abandonados durante lapsos de tiempo más o menos amplios, como sucede en Castellones de Céal. Existe pues una cierta continuidad ceremonial que debe reflejar la creación de una tradición nacida en esta época y mantenida con variaciones a lo largo de todo el primer milenio a.C. 
La presencia de estos nuevos grupos de población no solo se deduce de la evidencia funeraria, ya que en todos los casos reseñados las áreas restringidas para uso funerario se corresponden con asentamientos de larga secuencia y distintos patrones de distribución del poblamiento. Un mejor conocimiento de los datos de estos asentamientos combinados con los proporcionados por sus correspondientes áreas funerarias, permitirán plantear y ampliar la perspectiva con la que deben contemplarse la gestación inicio y desarrollo de los pueblos ibéricos de la Alta Andalucía.

En lo que se refiere a las perspectivas de futuro en la investigación, uno de los apartados que puede proporcionar matizaciones importantes a algunas de las propuestas de interpretación reseñadas son los análisis de los restos antropológicos que mediante la aplicación de los métodos de la Medicina Forense han permitido avances en el reconocimiento e identificación de determinados tipos de restos antropológicos como son los huesos cremados (Chapa 2000: 15). La aplicación de este tipo de analíticas debido al estado fragmentario y deteriorado de los restos antropológicos sometidos a la acción sistemática del fuego debe hacerse con cierto filtro de prudencia, como se ha revelado al comparar las diferencias en los resultados ofrecidos por distintos especialistas ante el mismo conjunto de restos (Chapa et alii 1998: 204).

Sin embargo a pesar de los matices y problemas en el diagnóstico del sexo y edad de los restos, la aplicación de este tipo de análisis, que en los yacimientos que nos ocupan solo se han realizado de manera sistemática en los casos de Cerrillo Blanco, Jaén capital y la cámara de Hornos, permitirían una matización importante en el análisis de las cremaciones como la de precisar el número de enterramientos efectuados. Dada la relativa representatividad de los enterramientos estudiados y las distintas posibilidades en cuanto al número de enterramientos por tumba documentados en publicaciones recientes (González Prats 2002:71, 143 y 180) poder confirmar el número de enterramientos, individual, doble, múltiple por tumba permitirá precisar las características del ritual y su desarrollo.

Otros protocolos analíticos que concitan la atención de los investigadores a la hora de precisar y matizar las interpretaciones sobre diferencias sociales, son los análisis de paleodieta a partir del carbonato estructural que se genera en las células al producir energía y que al integrarse en la estructura cristalina del hueso sobrevive al proceso de cremación (Chapa 2000: 15). Habitualmente intentamos "leer" las diferencias de status a través de los ajuares y las estructuras funerarias, sin embargo primeras interpretaciones sobre la estructura jerarquizada o no de una comunidad, así como aspectos de su orientación económica, pueden ser desveladas con una mayor fiabilidad, cuando no con cierta dosis de sorpresa, a partir de las pautas de nutrición (Tabernero et alii 1999).

Este mismo tipo de carbonato estructural permite en la actualidad analíticas que se presumían vedadas por la perdida de los componentes orgánicos de los huesos cremados. Se trata del análisis del Carbono 14 AMS, que el Laboratorio de Gröningen viene desarrollando últimamente con buenos niveles de contrastación con otros materiales clásicos comoel carbón de los quemaderos de la misma necrópolis (Lanting y Brindley 1999). Uno de los principales problemas de las manifestaciones funerarias que estudiamos, al igual que en momentos posteriores los de época ibérica es la posibilidad de precisión en las atribuciones cronológicas. A la escasez de trabajos sistemáticos sobre los elementos más significativos de los ajuares, habría que añadir la amplitud cronológica con la que sueles ser fechados. Al igual que en los enterramientos ibéricos una de las posibilidades de refinar la cronología es a través de las importaciones que como hemos visto caracterizan algunos de los conjuntos funerarios reseñados, pero el número de estas importaciones suele ser limitado y su cronología inicial no siempre coincide con su fecha de deposición, con lo que la pervivencia de determinados elementos es un factor que, dependiendo de la orientación de la investigación, afectará a la fecha que se propone. Se configura pues a partir de las posibilidades de los análisis del Carbono 14 AMS sobre los restos humanos cremados, una excelente oportunidad no solo para precisar los márgenes cronológicos del mundo funerario sino también a partir de su adecuada correlación con los datos de los asentamientos poder desentrañar el complejo proceso de formación y desarrollo de las comunidades a las que pertenecieron. 
Pero estas nuevas perspectivas de la investigación deberían dejar de depender de un registro azaroso, puntual y en ocasiones descontextualizado. El papel de las inversiones dedicadas a la investigación básica necesaria para avanzar en el conocimiento científico, parece estar en horas bajas frente al alza de las inversiones para la puesta en valor de determinados yacimientos. Complemento indispensable la segunda de la primera, solo la tendencia a la rentabilidad inmediata sin programas definidos explica esta tendencia a incompatibilizarlas y si no se modifican las carencias actuales en la investigación básica, la divulgación se convertirá en una fantasía sin apoyo científico alguno (Chapa, Pereira y Madrigal e.p.).

\section{BIBLIOGRAFÍA}

ARTEAGA, O. (1999): "La delimitación del territorio entre Cástulo y Obulco", en V. Salvatierra y C. Rísquez (eds): De las sociedades agrícolas a la Hispania romana. Jornadas Históricas del Alto Guadalquivir (Quesada, (1992-(1995): 95-141. Universidad de Jaén. Jaén.

AUBET, M. E. (1975): La necrópolis de Setefilla, en Lora del Río, Sevilla. El túmulo A. Programa de Investigaciones Prehistóricas II. CSIC. Barcelona.

- (1978): La necrópolis de Setefilla, en Lora del Río. El túmulo B. Programa de Investigaciones Protohistóricas III. CSIC. Barcelona.

BENDALA, M. (1995): “Componentes de la cultura tartessica”, Tartessos 25 años después (1968-1999): 255-264. Ayuntamiento de Jerez de la Frontera. Jerez de la Frontera.

BLANCO, A. (1987): "Las esculturas de Porcuna. I. Estatuas de guerreros", Boletín de la Real Academia de la Historia CLXXXIV: 405-445.

(1988a): "Las esculturas de Porcuna. II. Hierofantes y cazadores", Boletín de la Real Academia de la Historia CLXXXV: 1-27.

(1988b): "Las esculturas de Porcuna. III. Animalia", Boletín de la Real Academia de la Historia CLXXXV: 206-234.

BLANCO FREIJEIRO, A. (1959): "Excavaciones arqueológicas en la Provincia de Jaén", Boletín del Instituto de Estudios Gienenses. Año 6, $\mathrm{n}^{\circ}$ 22: 89-128.

(1965): "El ajuar de una tumba de Cástulo", Oretania. VII no (19): 7-60.

BLÁZQUEZ, J. M.; GARCÍA GELABERT, M.P. y LÓPEZ PARDO, F. (1985): Cástulo V. Excavaciones Arqueológicas en España 140. Ministerio de Cultura. Madrid.

BLÁZQUEZ, J. M. y VALIENTE, J. (1981): Cástulo III. Excavaciones Arqueológicas en España 117. Ministerio de Cultura. Madrid.

- (1982): "El poblado de La Muela y la fase orientalizante en Cástulo (Jaén)", Phönizer im Western. Sonderdruck aus Madrider Beiträge, band 8. Mainz am Rhein.

BONSOR, J. (1899): Les colonies agricoles preromaines de la vallée du Betis. Paris.

CARRASCO, J. y PACHÓN, J. A. (1986): "La Edad del Bronce en la Provincia de Jaén", Homenaje a Luis Siret (1934-1984): 361-377. Consejería de Cultura. Junta de Andalucía.

CARRASCO, J.; PACHÓN, J. A. y ANÍBAL, C. (1986): “Cerámicas pintadas del Bronce Final procedentes de Jaén y Córdoba", Cuadernos de Prehistoria de la Universidad de Granada 11: 199 ss.

CARRASCO, J.; PACHÓN, J. A.; PASTOR, M. y LARA, I. (1980): "Hallazgos del Bronce Final en la Provincia de Jaén. La necrópolis de Cerro Alcalá (Torres, Jaén)", Cuadernos de Prehistoria de la Universidad de Granada 5: 221-236.

CELESTINO, S. (2001): Estelas de guerrero y estelas diademadas. La precolonización y formación del mundo tartésico. Ed. Bellaterra. Barcelona. 
CHAPA BRUNET, T. (2000): "Aplicaciones de la Arqueología de la Muerte en la Prehistoria reciente de la península Ibérica", en Actas do $3^{\circ}$ Congresso de Arqueologia Peninsular. Vol. 5. Proto-Història da Peninsula Ibérica: 9-19. Porto: ADECAP.

CHAPA, T.; PEREIRA, J. y MADRIGAL, A. (e.p.): Las necrópolis ibéricas de la Alta Andalucía. Nuevas perspectivas en los albores del siglo XXI.

CHAPA, T.; PEREIRA, J.; MADRIGAL, A. y MAYORAL, V. (1998): La necrópolis ibérica de Los Castellones de Céal (Hinojares, Jaén). Consejería de Cultura. Junta de Andalucía. Universidad de Jaén. Sevilla.

CONTRERAS CORTÉS, F. (1982): "Una aproximación al urbanismo del Bronce Final en la Alta Andalucía. El Cerro de Cabezuelos (Úbeda, Jaén)", Cuadernos de Prehistoria de la Universidad de Granada 7: 307-321.

FERNÁNDEZ OXEA, J. R. (1950): "Lápidas sepulcrales de la Edad del Bronce en Extremadura", Archivo Español de Arqueología 78: 290-301.

FERRER PALMA, J. E. (1977): "La necrópolis megalítica de Fonelas (Granada): el sepulcro "Domingo I" y sus niveles de enterramiento", Cuadernos de Prehistoria de la Universidad de Granada 2: 173-211.

- (1978): "Serie de pulseras decoradas, pertenecientes al Bronce Final, halladas en un enterramiento secundario de la necrópolis megalítica de Fonelas (Granada)", Baetica I: 181-193.

GONZÁLEZ NAVARRETE, J. (1987): Escultura Ibérica de Cerrillo Blanco, Porcuna, Jaén. Diputación Provincial de Jaén. Instituto de Cultura. Jaén.

GONZÁLEZ PRATS, A. (2000): “Acerca del "campo de urnas" de Huerta del Pato (Munera, Albacete). Una nueva hipótesis sobre el ritual de la cremación en el Sudeste de la Península Ibérica", Scripta in Honorem Enrique A. Llobregat Conesa: 237-248. Alicante.

- (2002): La necrópolis de cremación de Les Moreres (Crevillente, Alicante, España). (s. IX-VIIA.C.). III Seminario Internacional sobre Temas Fenicios. Universidad de Alicante. Alicante.

GUTIÉRREZ SOLER, L. M. (1998): "Roma y el poder local en el territorio del oppidum de Giribaile", Actas del Congreso Internacional: Los Iberos, Príncipes de Occidente. Estructuras de poder en la sociedad ibérica: 401-412. Fundación La Caixa. Barcelona.

GUTIÉRREZ SOLER, L. M.; ROYO ENCARNACIÓN, M. A.; BARBA COLMENERO, V. y BELLÓN RUIZ, J. P. (1992): "Informe sobre la primera campaña de prospección arqueológica superficial en el Guadalimar medio-hinterland de Cástulo”, Anuario Arqueológico de Andalucía. Vol. II. Actividades Sistemáticas: 249-256. Sevilla.

LANTING, J. N. y BRINDLEY, A. L. (1999): "Fechando hueso cremado: la base científica", Trabajos de Prehistoria 56 (2): 137-140.

LORRIO ALVARADO, A. (1985): Las necrópolis de incineración en el Sudeste de la Península Ibérica. Memoria de Licenciatura. Universidad Complutense de Madrid.

MARÍN DÍAZ, N.; GENER BASALLOTE, J. M. y PÉREZ CRUZ, M. A. (1993-1994): "La ciudad iberoromana de Basti", Florentia Iliberritana 4-5: 323-333.

MERGELINA, C. (1943-1944): "Tugia. Reseña de unos trabajos", Boletín del Seminario de Estudios de Arte y Arqueología X: 13-32.

MOLINA, F. (1978) "Definición y sistematización del Bronce Tardío y Final en el Sudeste de la Península Ibérica", Cuadernos de Prehistoria de la Universidad de Granada 3: 159-232.

MOLINA, F.; DELA TORRE, F.; NÁJERA, T.; AGUAYO, P. y SÁEZ, L. (1979): "Excavaciones en Úbeda la Vieja y Cabezuelos (Jaén)", Actas del XV Congreso Nacional de Arqueología Lugo (1977): 287-296.

MOLINA, F.; MENDOZA, A.; SÁEZ, L.; ARTEAGA, O.; AGUAYO, P. y ROCA, M. (1983): “Nuevas aportaciones para el estudio del origen de la Cultura Ibérica en la Alta Andalucía. La campaña de (1980 en el Cerro de los Infantes", Actas del XVI Congreso Nacional de Arqueología: 689-707. Murcia-Cartagena (1982). Zaragoza. 
MOLINOS, M.; RÍSQUEZ, C.; SERRANO, J. L. y MONTILLA, S. (1994): Un problema de fronteras en la periferia de Tartessos: Las Calañas de Marmolejo (Jaén). Universidad de Jaén, Jaén.

MONTEAGUDO, L. (1977): Die Beile auf der iberischen Halbinsel. Prähistorische Bronzefunde. Abteilung IX. Band 6. C.H. Beck'sche Verlagsbuchhalndlung. Munich.

NEGUERUELA, I. (1990): Los monumentos escultóricos ibéricos del Cerrillo Blanco de Porcuna (Jaén). Ministerio de Cultura. Madrid.

NEGUERUELA MARTÍNEZ, I. y RODRÍGUEZ RUS, P. (1986): “Campaña de excavaciones en 'Cerro Alcalá' (Jimena/Torres, Jaén)", Anuario Arqueológico de Andalucía. Vol. II Actividades Sistemáticas: 389-391.

NEGUERUELA MARTÍNEZ, I.; RODRÍGUEZ RUS, P. y AVELLA DELGADO, L. (1987): "Informe preliminar de la campaña de excavaciones de (1987 en la necrópolis "Las Tosquillas". Cerro Alcalá (Torres, Jaén)", Anuario Arqueológico de Andalucía. T. II. Actividades Sistemáticas: 294-300.

PELLICER, M: y SCHÜLE, W.(1962): El Cerrodel Real. Galera(Granada). Excavaciones Arqueológicas en España 12. Ministerio de Educación Nacional. Madrid.

- (1966): El Cerro del Real. Galera (Granada). El corte estratigráfico IX. Excavaciones Arqueológicas en España 52. Ministerio de Educación Nacional. Madrid.

PEREIRA SIESO, J.; MADRIGAL BELINCHÓN, A. y CHAPA BRUNET, T. (1998): "Enterramientos múltiples en las necrópolis ibéricas del Guadiana Menor. Algunas consideraciones", Actas del Congreso Internacional: Los Iberos, Príncipes de Occidente. Estructuras de poder en la sociedad ibérica: 343-354. Fundación La Caixa. Barcelona.

PRESEDO VELO, F. (1973): La Dama de Baza. Museo Arqueológico Nacional. Madrid.

- (1982): La Necrópolis de Baza. Excavaciones Arqueológicas en España 119. Ministerio de Cultura, Madrid.

RUIZ, A. (1998): "Los príncipes ibéricos: procesos económicos y sociales", Actas del Congreso Internacional: Los Iberos, Príncipes de Occidente. Estructuras de poder en la sociedad ibérica: 289-300. Fundación La Caixa. Barcelona.

RUIZ-GÁLVEZ PRIEGO, M. (1992): "La novia vendida: orfebrería, herencia y agricultura en la Protohistoria de la Península Ibérica”, SPAL 1: 219-251.

- (1995): "Cronología de la Ría de Huelva en el marco del Bronce Final de Europa Occidental", en Ruiz Gálvez Priego, M. (ed.): Ritos de Paso y Puntos de Paso. La Ría de Huelva en el Mundo del Bronce Final Europeo. Complutum Extra 5: 79-83.

RUIZ MATA, D. y PÉREZ, C. (1989): "El túmulo I de la necrópolis de Las Cumbres (Puerto de Santa María, Cádiz)", Tartessos. Arqueología Protohistórica del Bajo Guadalquivir: 287-295. Sabadell.

SÁNCHEZ, M. (1994): Las necrópolis tumulares de Los Alcores (Sevilla). Servicio de Publicaciones. Universidad de Cádiz. Cádiz.

SÁNCHEZ QUIRANTE, L. (1999): "El guerrero y el Museo Municipal de Baza", El guerrero de Baza: 41-48. Consejería de Cultura. Junta de Andalucía.

SIRET, L. (1913): Questions de Chronologie et d'Ethnographie ibèriques. T. I. Paris.

TORRECILLAS GONZÁLEZ, J. F. (1985): La necrópolis de época tartésica del 'Cerrillo Blanco'(Porcuna, Jaén). Diputación Provincial. Jaén.

TORRES ORTIZ, M. (1999): Sociedad y Mundo funerario en Tartessos. Real Academia de la Historia. Bibliotheca Archaeologica Hispana 3. Madrid.

UNTERMANN, J. (1985): "Lenguas y unidades políticas del suroeste hispánico en época prerromana", en Ch. Wentlaff-Eggebert (ed) De Tartessos a Cervantes: 1-40. Köln-Wien. 


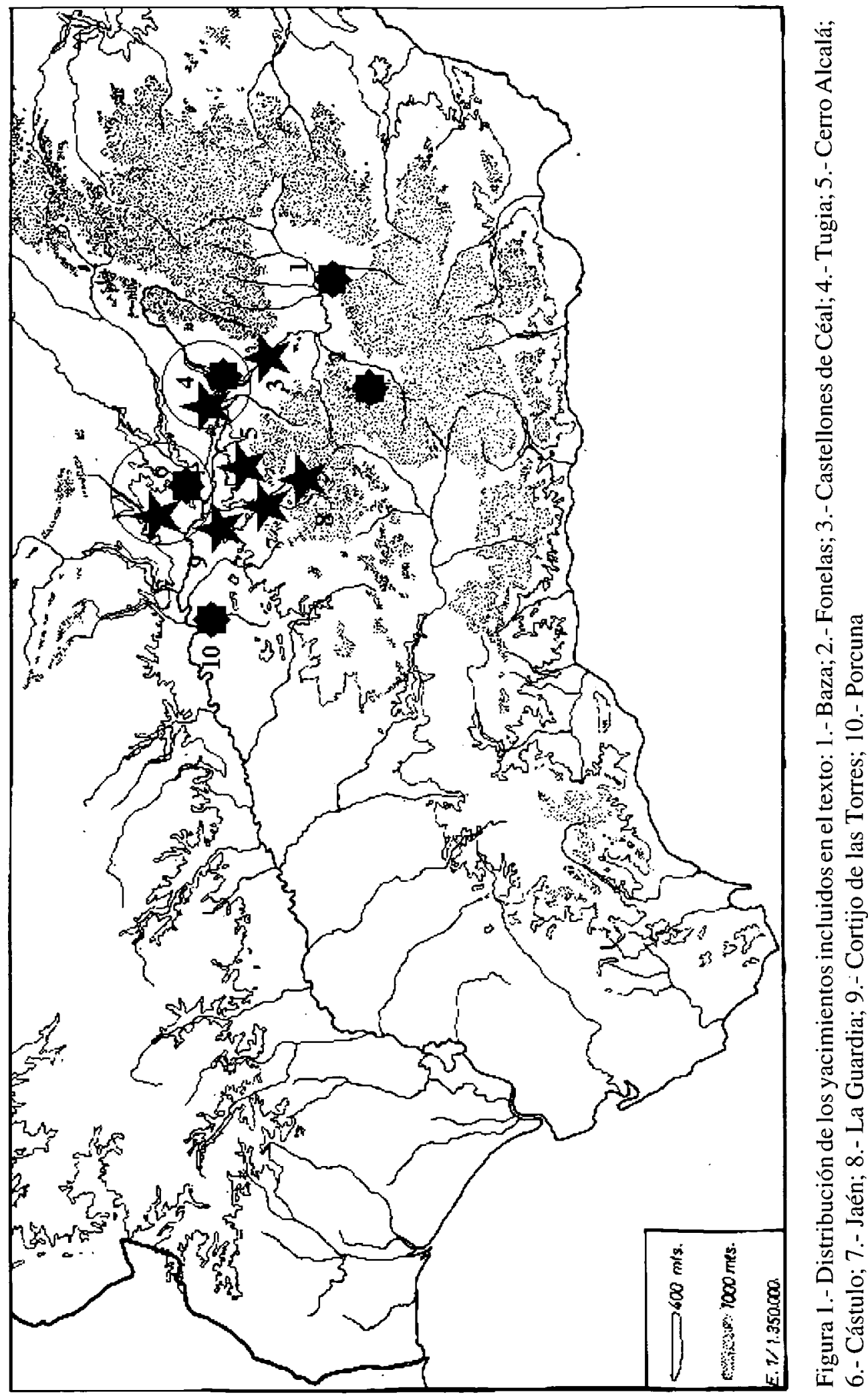




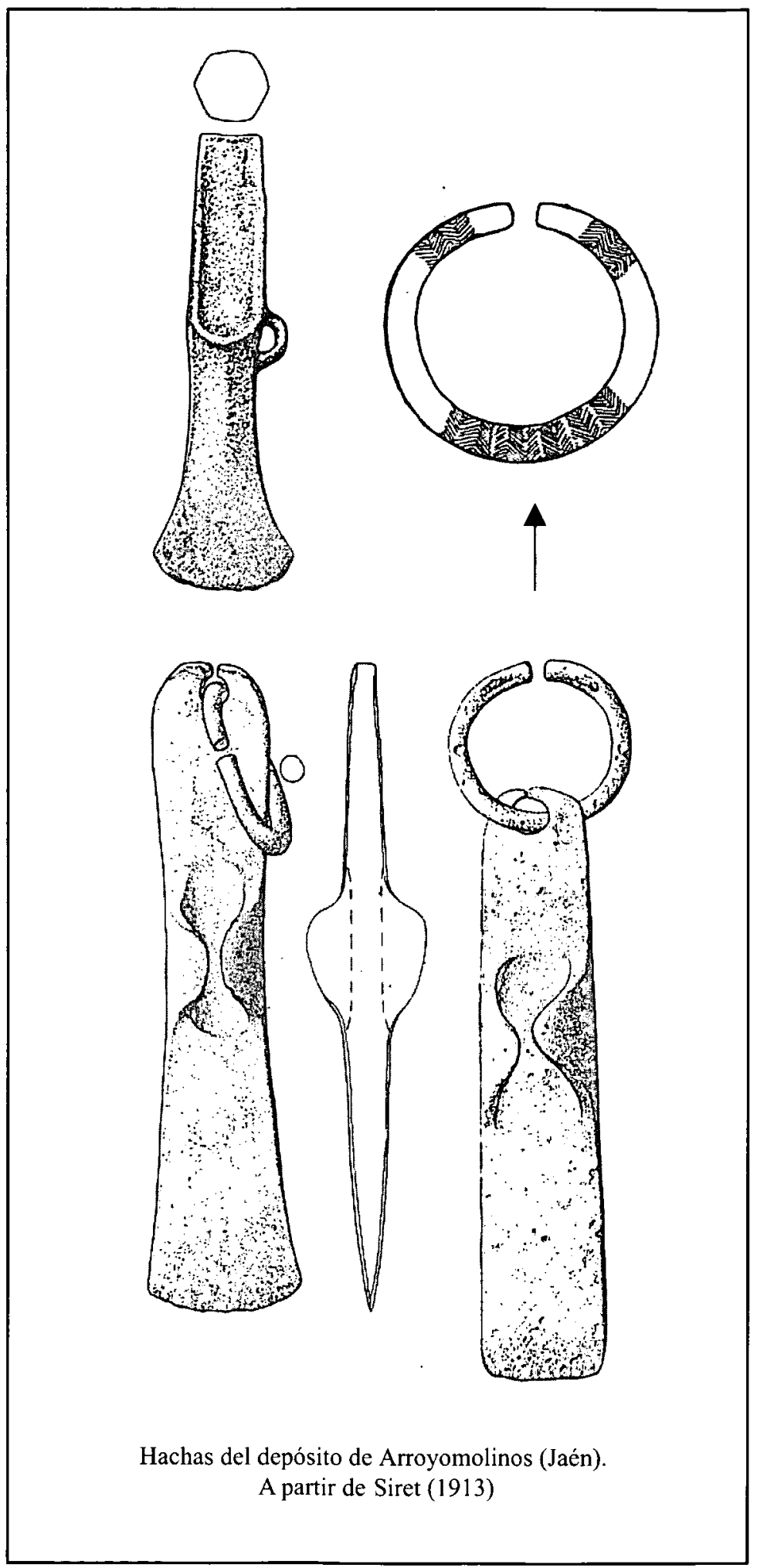

Figura 2.- Depósito de Arroyomolinos (según Siret 1913 y Monteagudo 1977) 


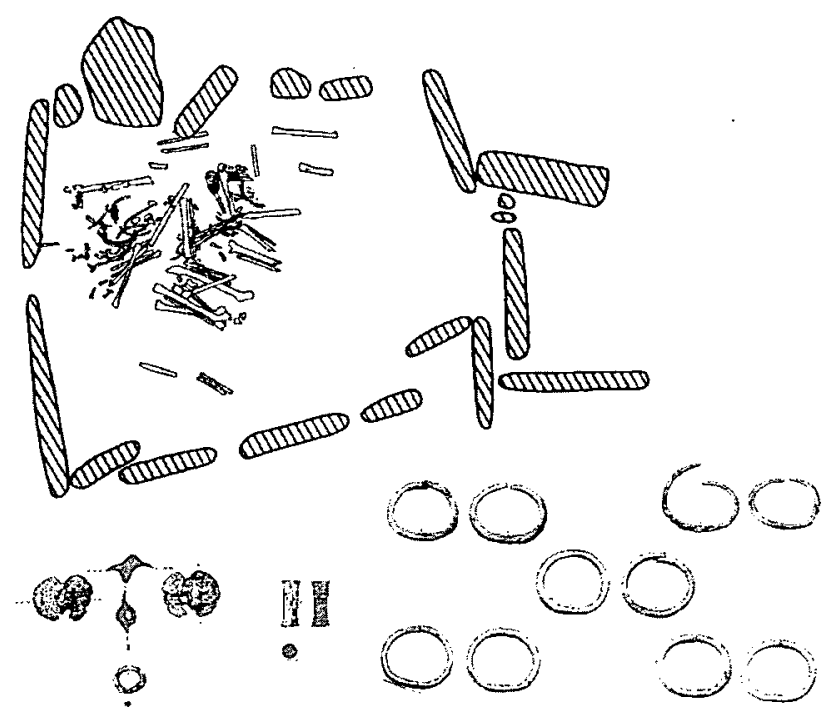

A
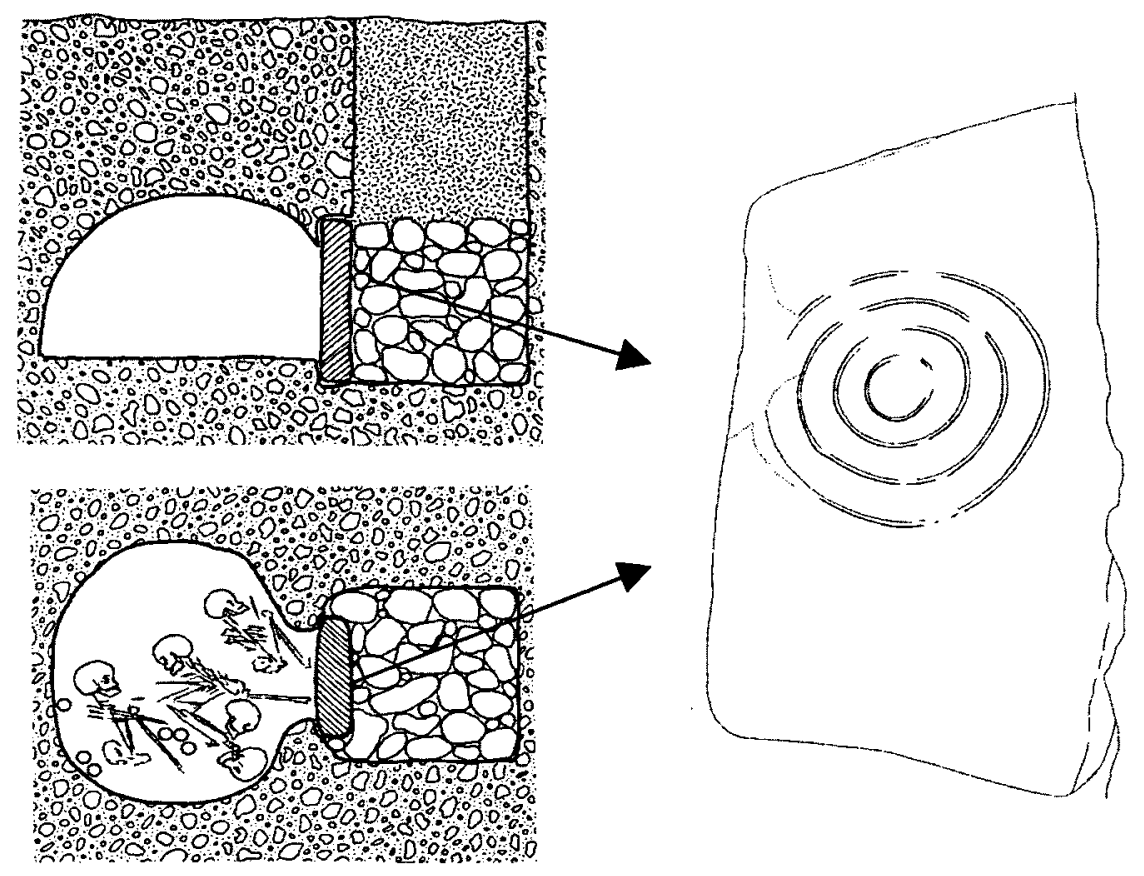

B

Figura 3.- A.- Fonelas (Granada). Planta y ajuar del nivel superior del enterramiento múltiple "Domingo I" (según Ferrer Palma 1977).

B.- Toya (Jaén) Tumba de Haza de Trillo (a partir de Mergelina 1943-44 y Blech 2001). 


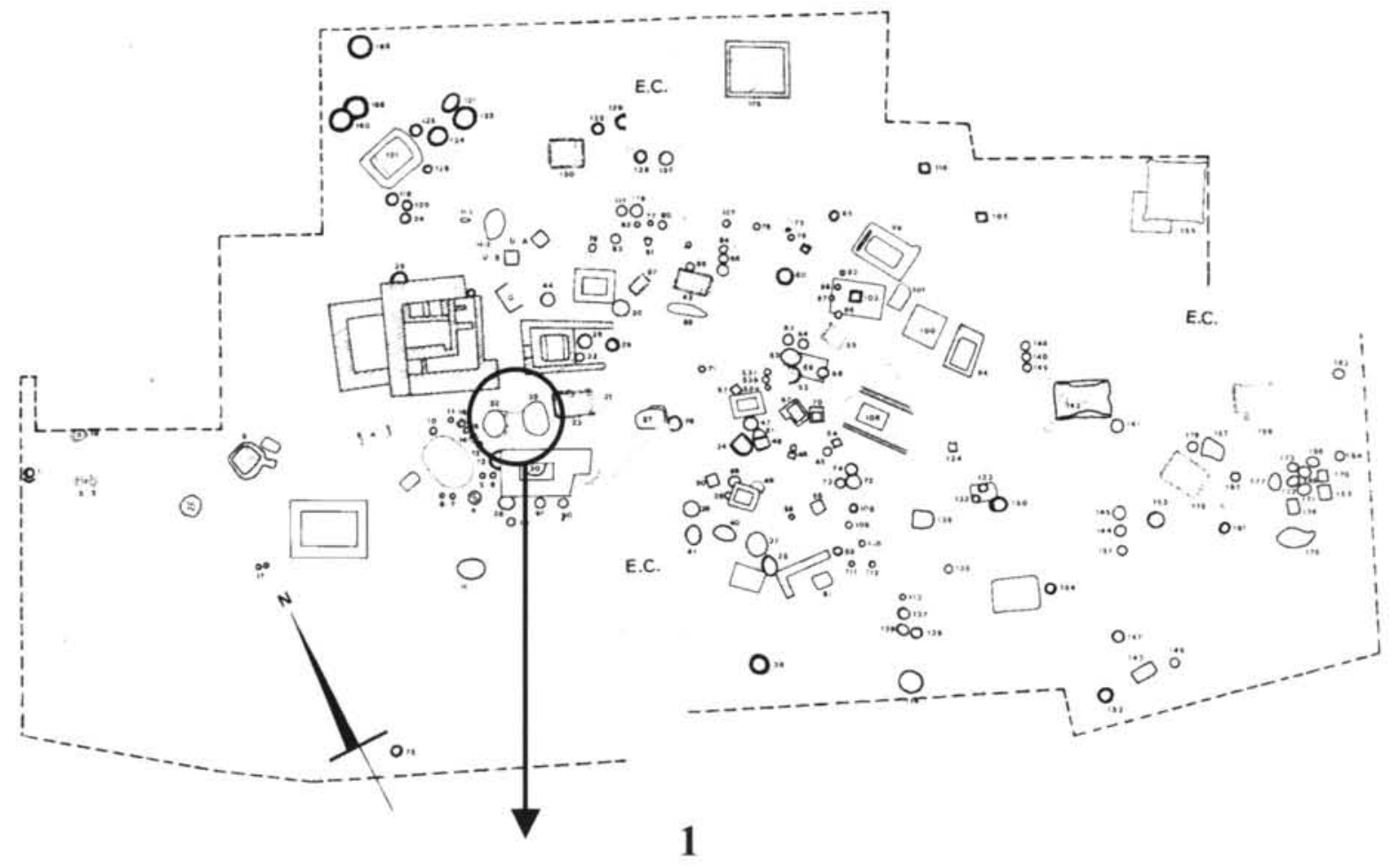

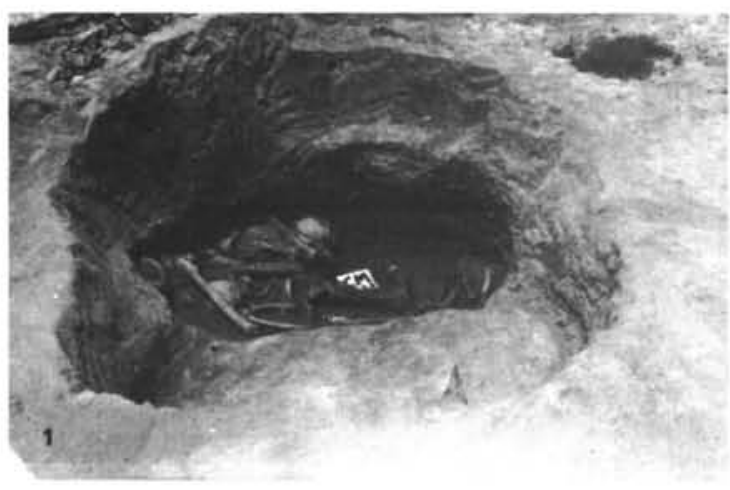

2

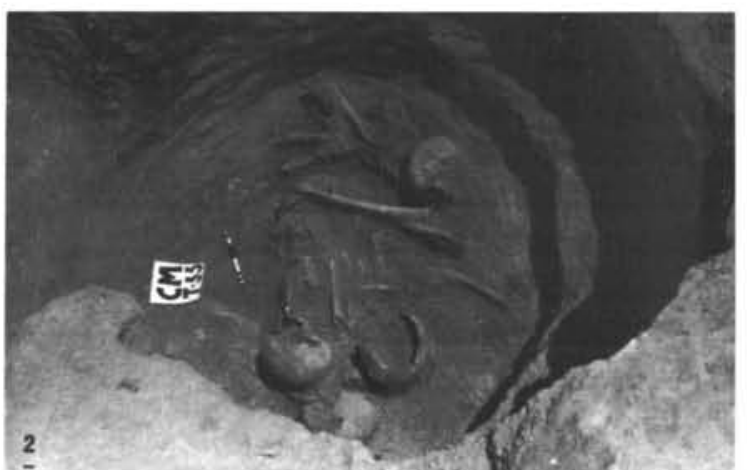

3

Figura 4.- Necrópolis de Baza (Granada) y tumbas 32 y 33 (a partir de Presedo 1982) 

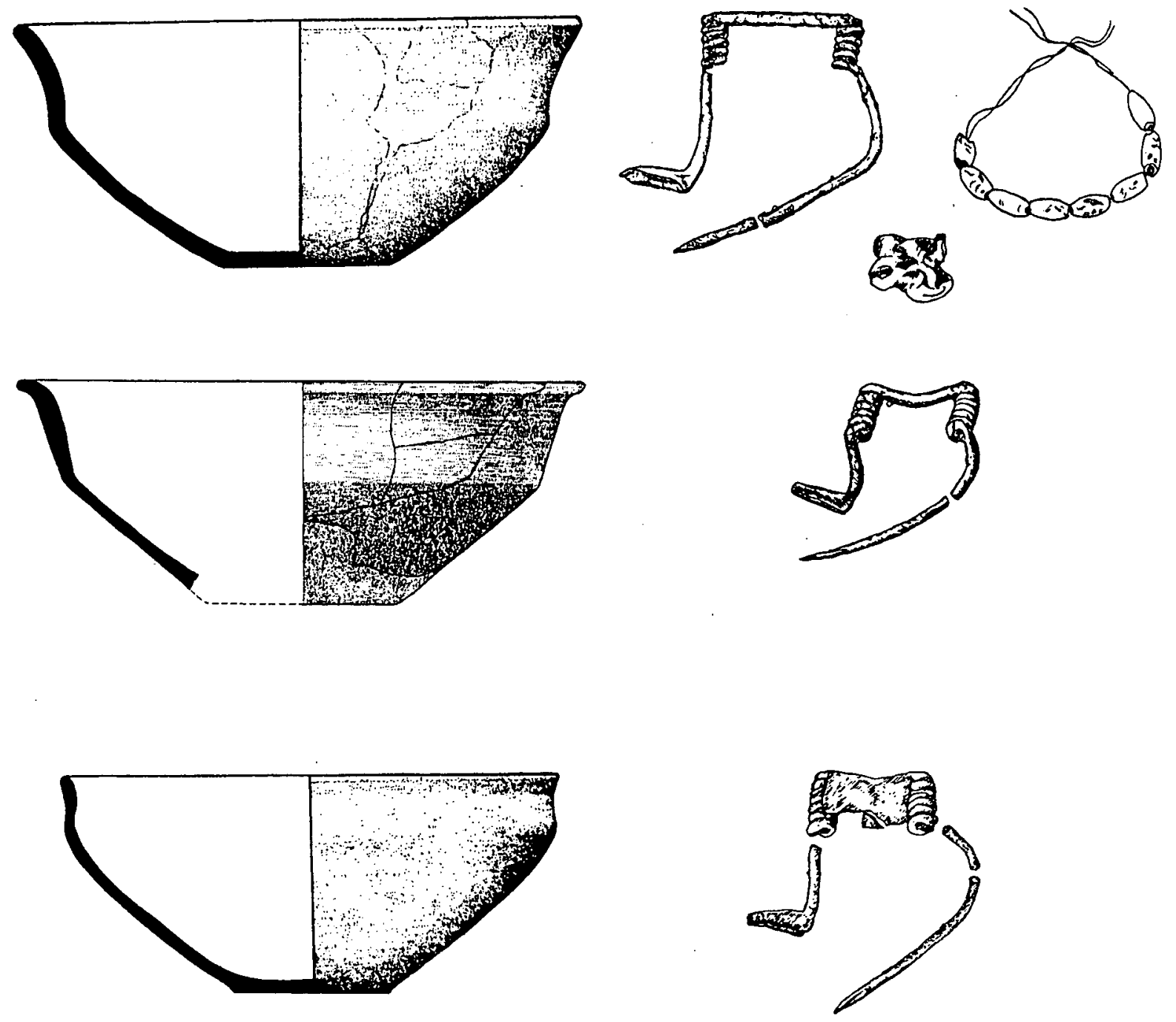

Figura 5.- Castellones de Céal (Jaén). Enterramientos de la fase inicial de la necrópolis. 

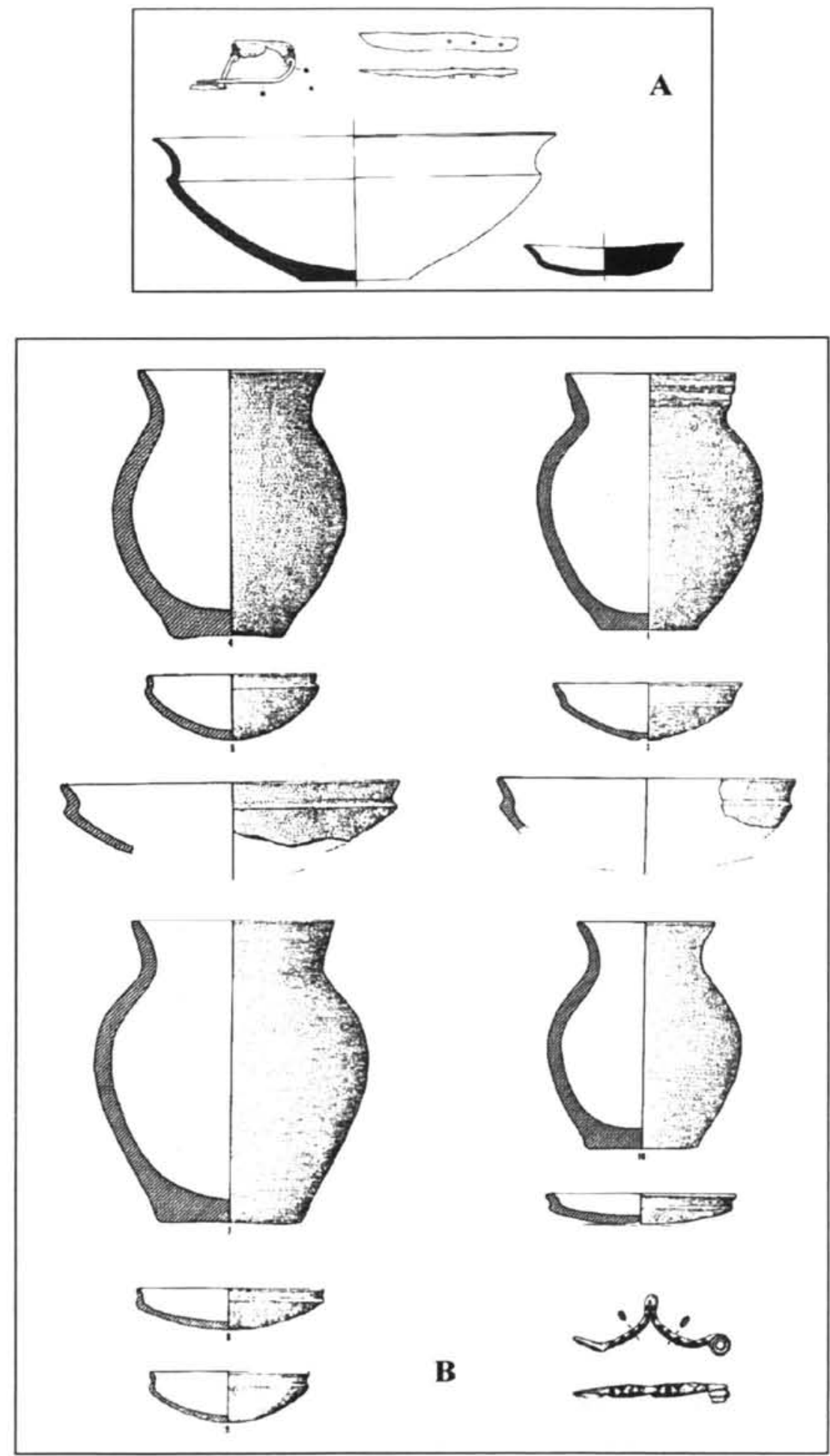

Figura 6.- Cerro Alcalá (Jaén). A.- Enterramiento de Las Tosquillas (según Negueruela, Rodríguez y Avella 1991); B.- Enterramientos de incineración doble (a partir de Carrasco et alii 1980). 


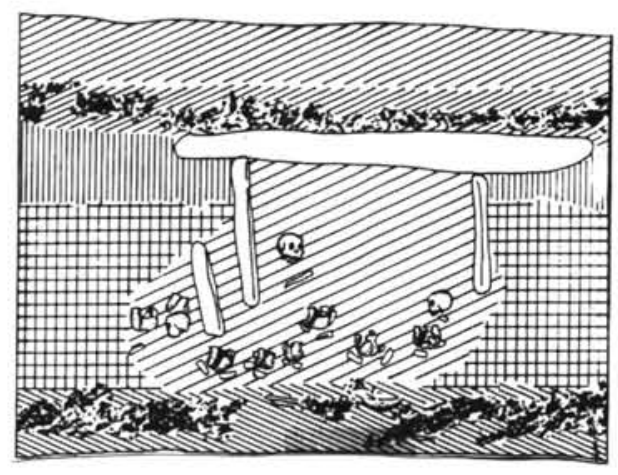

A
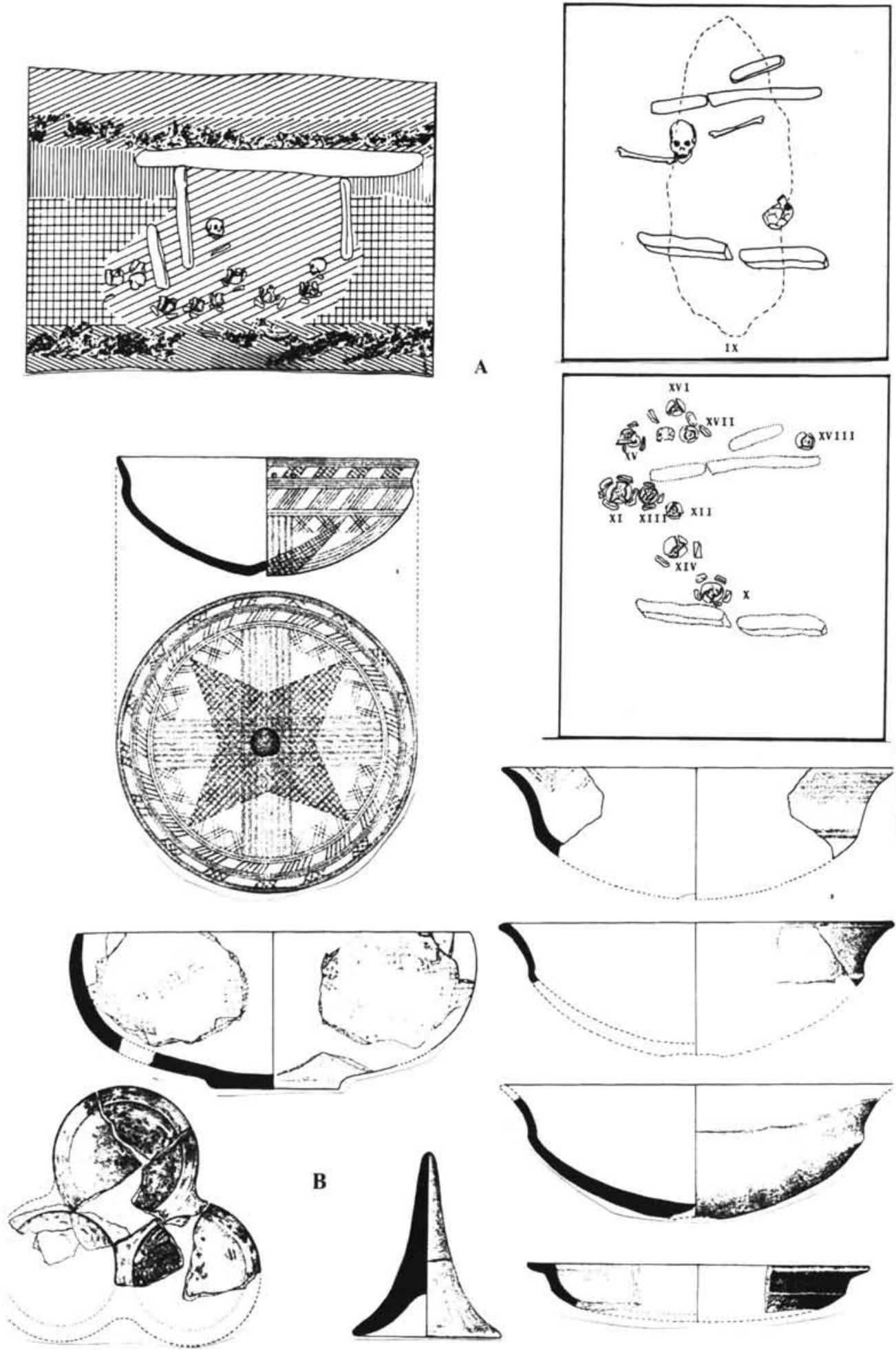

B
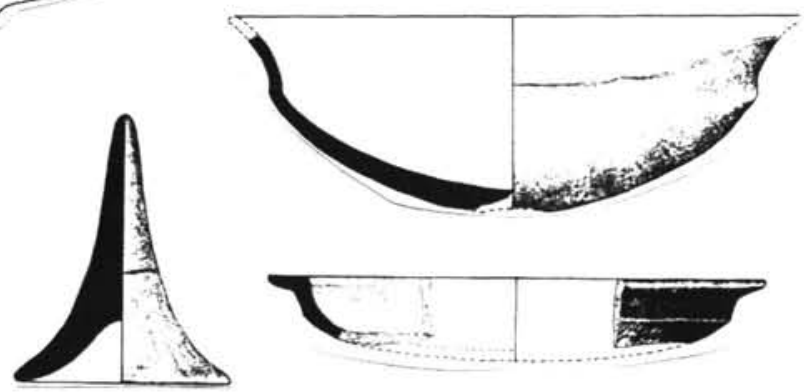

Figura 7.- Cástulo (Jaén). A: Plano, perfil y enterramiento de inhumación del Corte 1 de Los Patos; B.- Materiales de la tumba XIX del nivel inferior del Corte 1 (a partir de Blázquez 1975). 


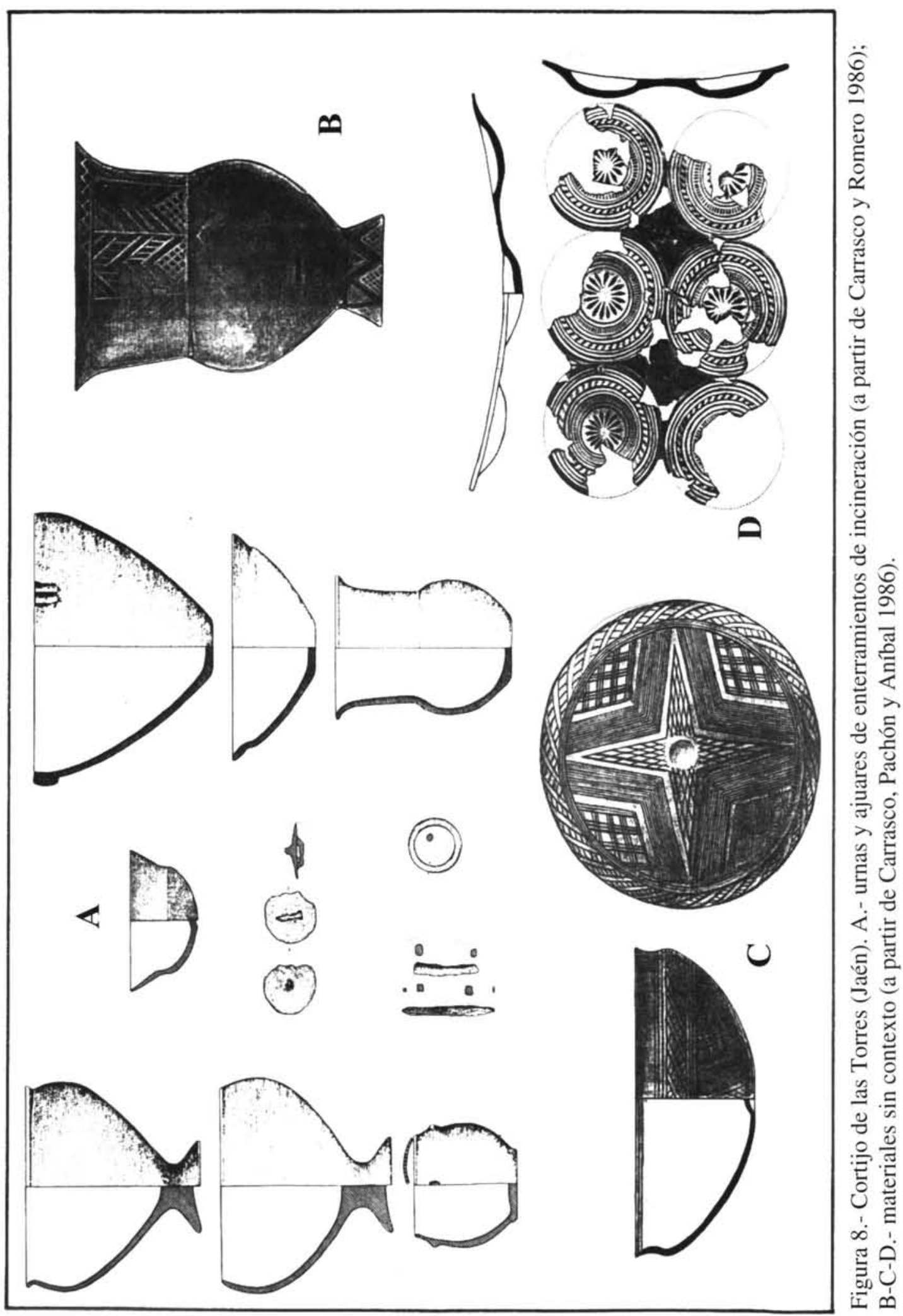

ISSN: 1133-4525 ISSN-e: 2255-3924 

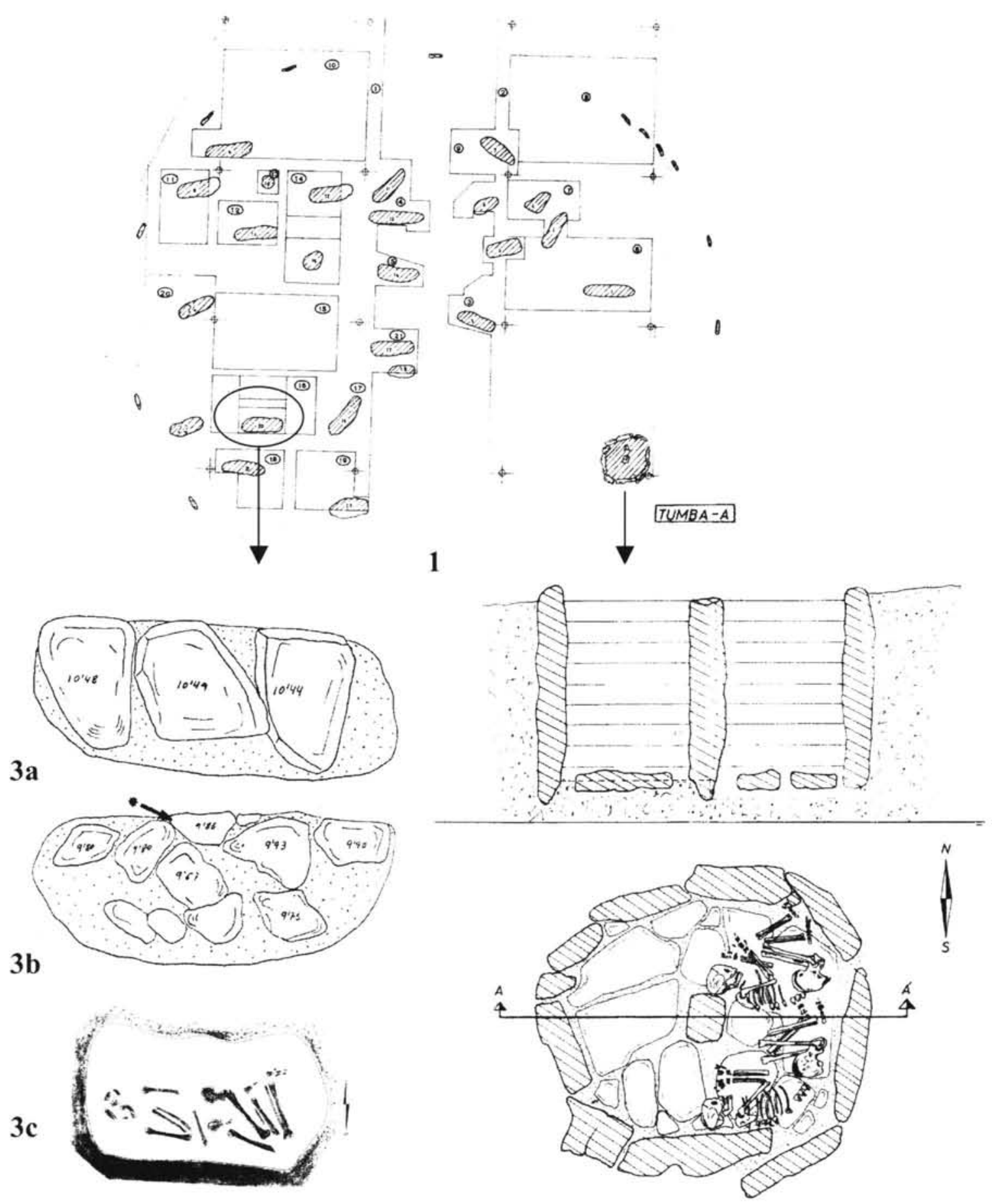

2

Figura 9.- Cerrillo Blanco (Jaén). 1 Plano de la necrópolis; 2 sección y planta de la tumba de cámara; 3 a, b y c distintas capas del enterramiento $\mathrm{n}^{\circ} 20$ (a partir de Torrecillas González 1985). 


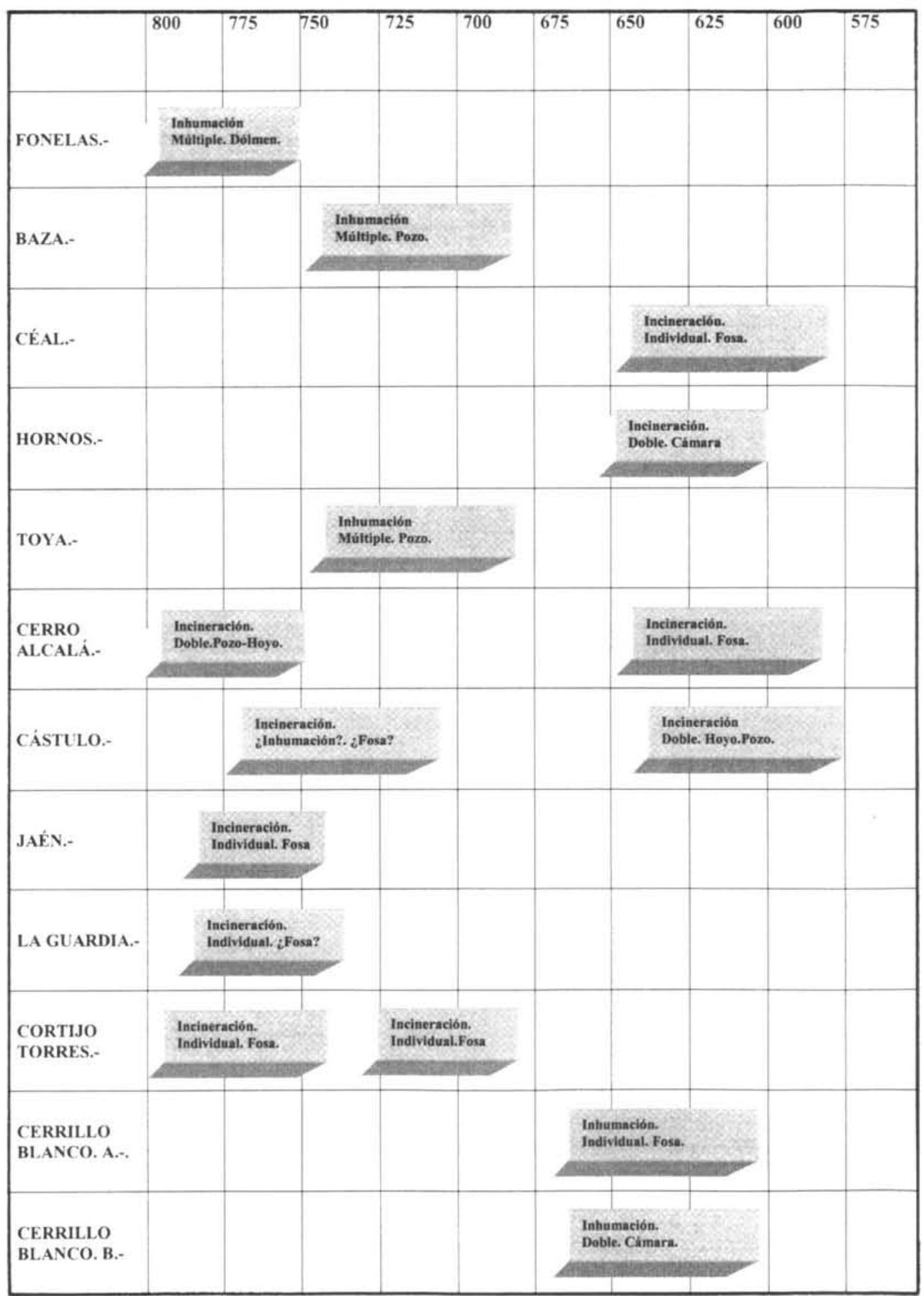

Figura 10.- Resumen cronológico de los rituales y tipos de enterramiento de los yacimientos citados en el texto. 